\title{
Eating and Mealtime Behaviors in Patients with Autism Spectrum Disorder: Current Perspectives
}

This article was published in the following Dove Press journal:

Neuropsychiatric Disease and Treatment

Lucia Margari

Lucia Marzulli

Alessandra Gabellone Concetta de Giambattista

Child Neuropsychiatric Unit, University of Bari Aldo Moro, Bari, Italy
Correspondence: Lucia Margari

Child Neuropsychiatric Unit, University

of Bari Aldo Moro, Piazza Giulio Cesare,

II, Bari 70124, Italy

Tel +39805592829

Email lucia.margari@uniba.it
Abstract: Autism spectrum disorder (ASD) is a neurodevelopmental disorder characterized by impaired social and communication skills and repetitive and restrictive behaviors. Children and adolescents with ASD are more likely to present feeding problems than their typically developing peers are. The present narrative review of literature aims to highlight the most recent evidence about epidemiology and presentations of eating and mealtime behavioral abnormalities in ASD from infancy to adolescence. Abnormalities in breastfeeding and acceptance of complementary foods have been described by most of the studies evaluating ASD early feeding history. Among the various eating and mealtime behaviors identified in ASD children and adolescents, the most common was food selectivity. The present review also provides brief overviews of the various aspects of food that may influence food acceptance by ASD patients and of the correlation between eating problems and ASD core symptoms, as well as with cognitive level, language skills, and family environment. However, studies evaluating eating problems in ASD children and adolescents are very heterogeneous and they show methodological differences. Moreover, the absence of unique definitions of eating and mealtime behaviors in ASD further limits the comparability of studies.

Keywords: autism spectrum disorder, feeding, infancy, childhood, adolescence

\section{Introduction}

Autism spectrum disorder (ASD) is a neurodevelopmental disorder characterized by impaired social and communication skills and repetitive and restrictive behaviors. ${ }^{1}$ According to data collected by the Center for Diseases Control and Prevention (CDC) of Atlanta, ASD prevalence amounted to 1-2\% during 2014 in the USA, with an estimated male-female ratio of $4: 1 .^{2}$

In addition to core symptoms, ASD clinical features also include aberrant eating behaviors. Although some types of eating disturbances, such as food refusal, are also frequent in the general pediatric population, their prevalence appears to be significantly higher in ASD children, ${ }^{3}$ with percentages ranging from $51 \%$ to $89 \%{ }^{4-10}$

The origin of eating abnormalities in ASD children is believed to be multifactorial, including behavioral, cognitive, and environmental causes. ${ }^{11}$ In particular, among the behavioral factors that can condition eating behaviors, there are the symptoms of repetitiveness and rituals, including fear of novelty, inflexibility, need for sameness, but also hypo or hyper-reactivity to sensory stimuli. The alteration of the sensory processing described in ASD patients ${ }^{12}$ may, in fact, make mealtime challenging for 
ASD individuals, given the high rate of stimulus coming from food and environment during mealtime.

Feeding difficulties can influence the health status of the child and represent a source of concern and stress for parents. Thus, a better knowledge of eating abnormalities in ASD is desirable in order to widen the evidence base for treatment that is necessary to open new avenues for the most effective intervention strategies.

On this basis, the purpose of the present review is to update the main current knowledge about epidemiology and presentations of eating and mealtime behavioral abnormalities in ASD individuals from infancy to adolescence.

\section{Materials and Methods}

A web-based review of the literature was performed to identify all studies reporting on clinical features of eating problems (EP) in ASD children and adolescents. A narrative review format was chosen.

The search strategy was originally created and was conducted in the PUBMED database,SCOPUS database, COCHRANE LIBRARY database, and PUBPSYCH database. The following keywords were used: "eating," "feeding," "food selectivity," "mealtime," "diet," AND "autism." Additional articles were manually identified by reviewing article references. Inclusion criteria were: (a) original articles published between January 2010 and December 2019; (b) report of any data regarding clinical features of eating behavior in ASD people; (c) papers directly focused on children and adolescents; (d) English language; (e) sample size greater than 15 participants. We excluded: (a) review, meta-analysis articles, book chapters, or case report/case series articles; (b) papers in which participants did not receive a full diagnosis of ASD (ie, with "autistic traits"); (c) studies dealing with eating disorders identified with distinct diagnosis as anorexia nervosa or bulimia nervosa; (d) studies conducted on animal models; (e) articles referred to specific genetic mutations or syndromes. The resulting narrative review includes two sections. The first section presents evidence on early feeding history in ASD patients, in particular: breastfeeding, weaning, and addition of complementary foods. The second section focuses on the most common eating and mealtime behaviors identified in ASD children and adolescents.

\section{Results}

The primary literature search, conducted in May 2020, identified 4310 records from four databases. After removing duplicates between databases, we operated a first screening based on abstracts. Then, 116 full texts were read and analyzed for eligibility by two authors independently. Any disagreement was resolved through discussion. According to the inclusion/exclusion criteria, 60 articles were excluded, and 56 original articles were retained for the final analysis. Three additional studies were identified in the course of the bibliographical analysis. The current review includes a total of 59 papers. A flow diagram of the screening process can be seen in Figure 1.

Study features are summarized in Table 1.

We found thirty-one case-control studies and twentyeight cross-sectional studies. The age of ASD participants ranged from 9 months to 18 years.

In fifty papers, which enrolled both males and females, a major prevalence of males was found. In four papers, the exact male:female ratio is not indicated. Two studies had an exclusively male sample, and two other studies an only female sample.

ASD was diagnosed according to the Diagnostic and Statistical Manual of Mental Disorder (DSM) or

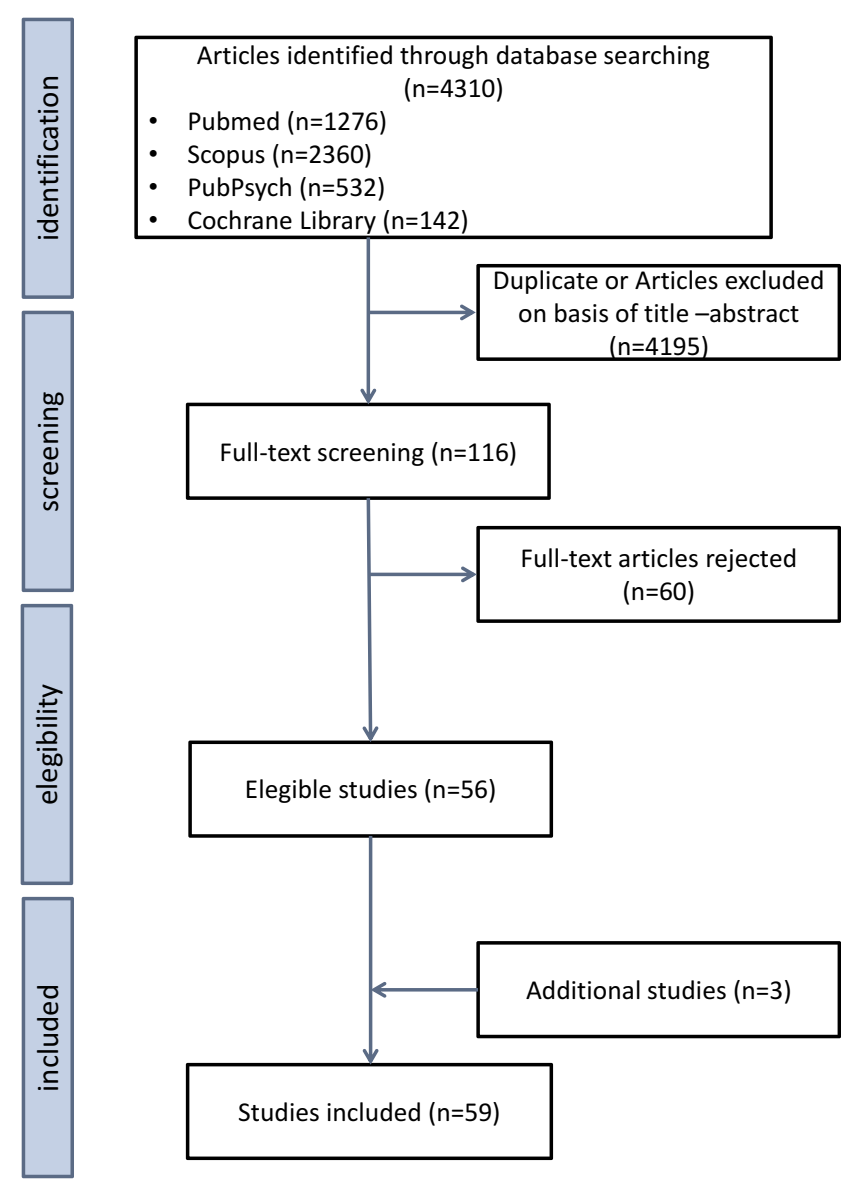

Figure I Flow diagram of the screening procedure. 


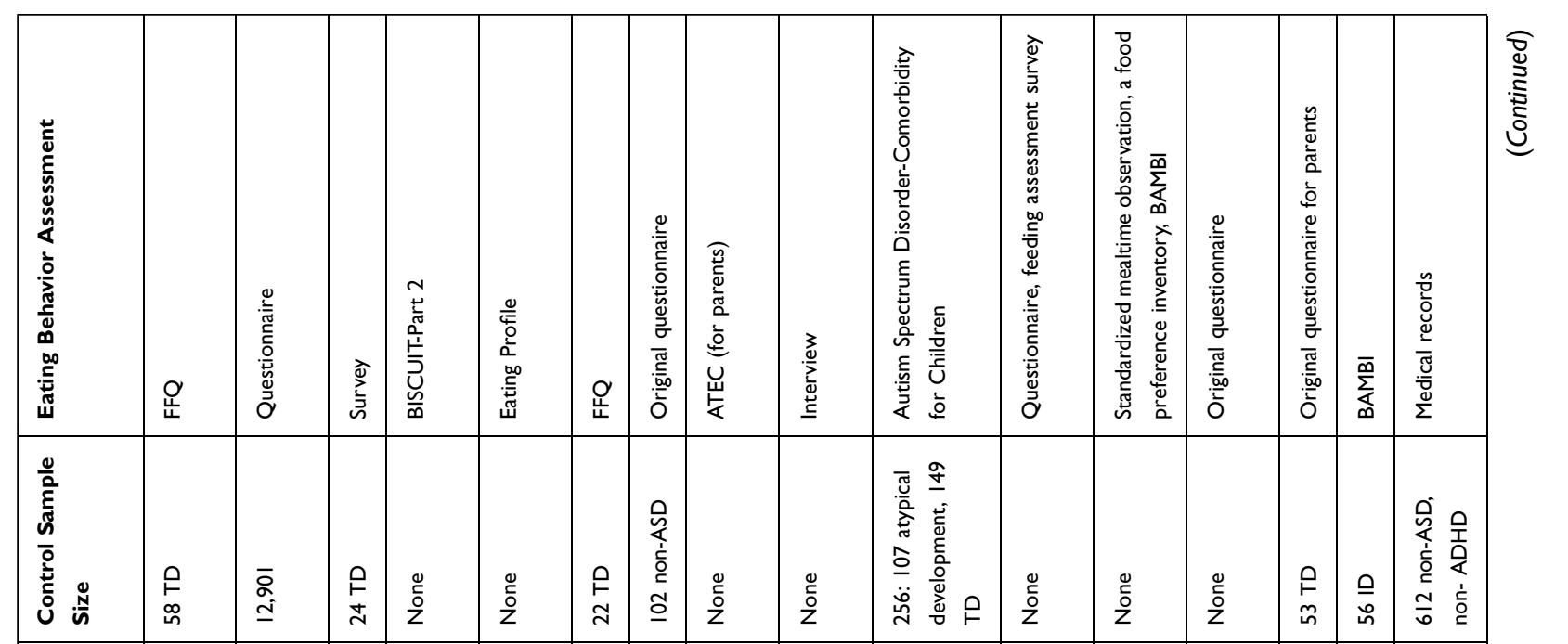

\begin{tabular}{|c|c|c|c|c|c|c|c|c|c|c|c|c|c|c|c|c|}
\hline 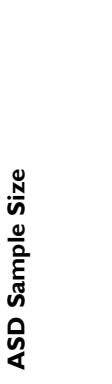 & $\tilde{n}$ & $\curvearrowright$ & $\stackrel{ \pm}{N}$ & 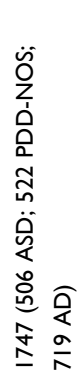 & ณ & $\pi$ & $\underline{\text { s }}$ & 呙 & 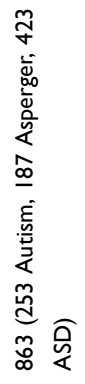 & 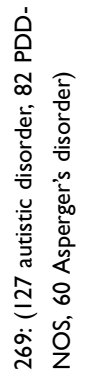 & $\underline{\mathbf{t}}$ & p & ก & $\tilde{n}$ & $\bar{\sigma}$ & $\bar{m}$ \\
\hline 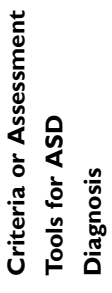 & $\stackrel{\tilde{z}}{z}$ & $\begin{array}{l}\underline{0} \dot{1} \\
\underline{0}\end{array}$ & 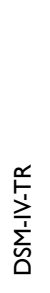 & $\widetilde{\tilde{z}}$ & $\tilde{z}$ & $\tilde{z}$ & 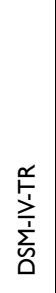 & 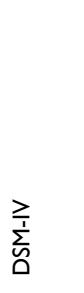 & $\begin{array}{l}\underline{0} \dot{\hat{\theta}} \\
\underline{0}\end{array}$ & 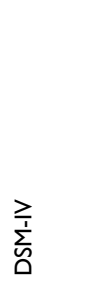 & $\sum_{\substack{i \\
\Delta}}^{\geq}$ & $\tilde{z}$ & $\tilde{z}$ & 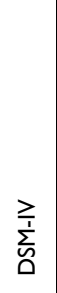 & $\begin{array}{l}\underline{0} \\
\underline{\hat{\theta}}\end{array}$ & 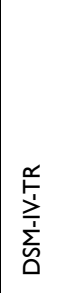 \\
\hline 㞱 & $\overline{\dot{\alpha}}$ & $\begin{array}{c}\overline{\phi \theta} \\
\dot{0}\end{array}$ & $\overline{\dot{m}}$ & 广্ं & ö & $\overline{\overline{\ddot{O}}}$ & $\overline{\dot{m}}$ & $\overline{\stackrel{i}{0}}$ & 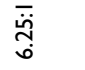 & $\overline{\stackrel{M}{\sim}}$ & $\overline{\dot{f}}$ & 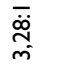 & 蒿 & $\overline{\ddot{\dot{\omega}}}$ & $\begin{array}{l}\overline{\ddot{\alpha}} \\
\stackrel{\leftrightarrow}{\infty}\end{array}$ & $\overline{\ddot{i n}}$ \\
\hline 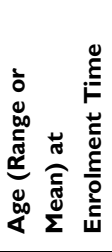 & बें $\overline{\dot{m}}$ & $\underline{\lambda}$ & 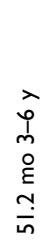 & 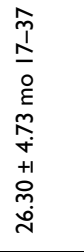 & $\begin{array}{l}\hat{n} \\
\stackrel{1}{+} \\
\text { +1 } \\
\stackrel{n}{n}\end{array}$ & 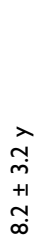 & $\begin{array}{l}\hat{a} \\
\stackrel{i}{1} \\
+1 \\
0 \\
0 \\
0\end{array}$ & $\begin{array}{l}\lambda \\
m \\
+1 \\
\infty \\
\infty \\
0\end{array}$ & $\frac{\widehat{\infty}}{\lambda}$ & $\begin{array}{l}\frac{\lambda}{\infty} \\
\frac{0}{1} \\
\lambda \\
0 \\
0 \\
\infty \\
\infty\end{array}$ & $\frac{\hat{\infty}}{\vec{l}}$ & $\begin{array}{l}\hat{\alpha} \\
0 \\
m\end{array}$ & $\begin{array}{l}\stackrel{\circ}{\varepsilon} \\
\infty \\
\stackrel{0}{0} \\
\underline{0}\end{array}$ & 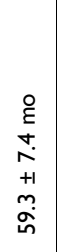 & 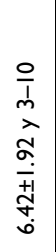 & 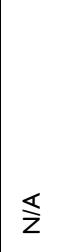 \\
\hline 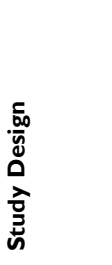 & 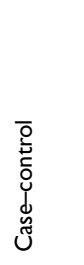 & 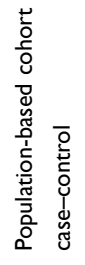 & 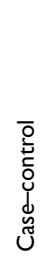 & 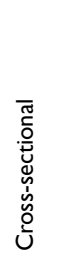 & 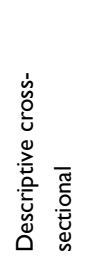 & 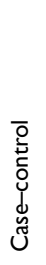 & 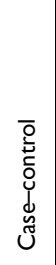 & 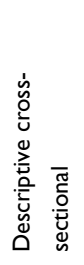 & 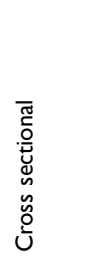 & 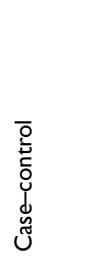 & 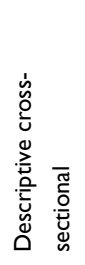 & 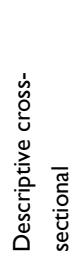 & 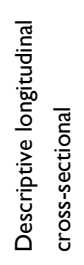 & 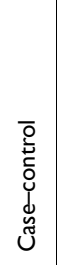 & 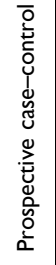 & 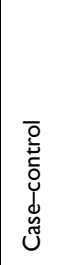 \\
\hline 㟈 & 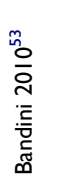 & 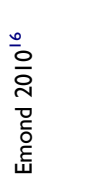 & 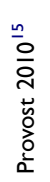 & 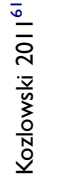 & 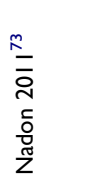 & 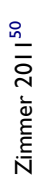 & 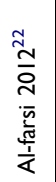 & 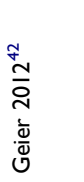 & 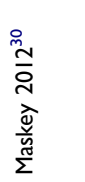 & 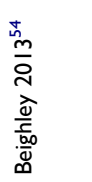 & 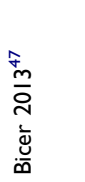 & 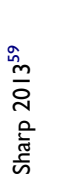 & 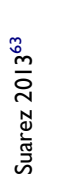 & 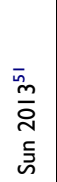 & 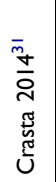 & 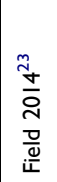 \\
\hline
\end{tabular}




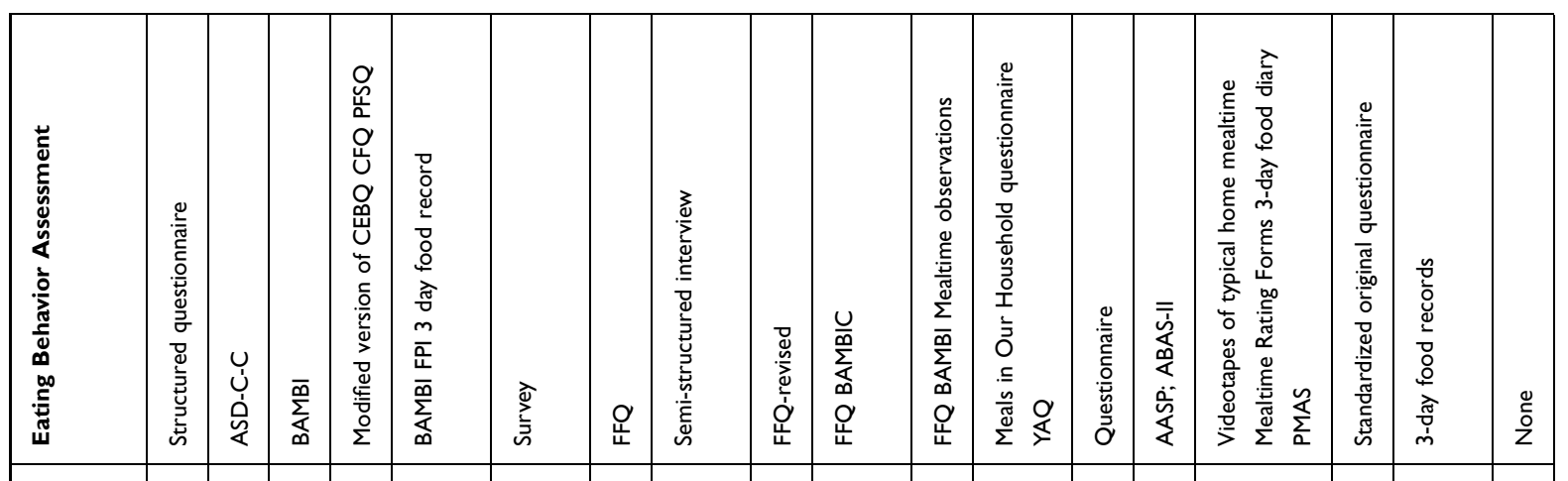

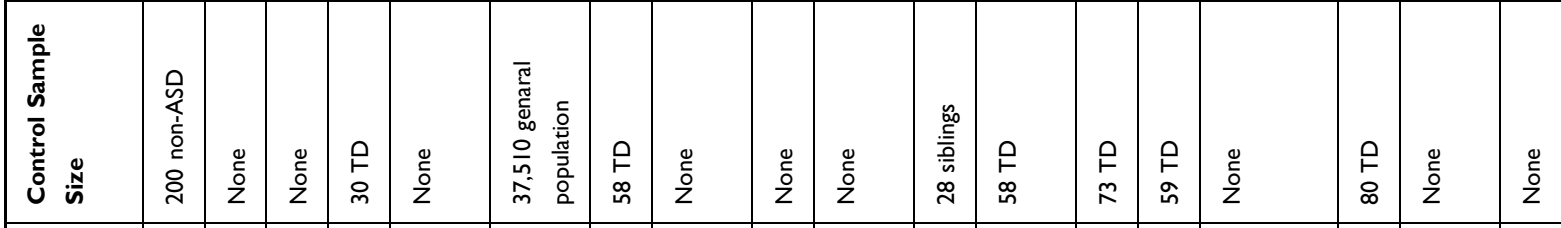

\begin{tabular}{|c|c|c|c|c|c|c|c|c|c|c|c|c|c|c|c|c|c|c|}
\hline 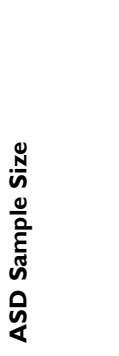 & $\underline{q}$ & 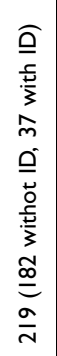 & ڤ̊ & $\ddot{n}$ & $\tilde{\sim}$ & $\bar{\rho}$ & $\tilde{n}$ & $\underline{a}$ & 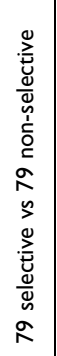 & 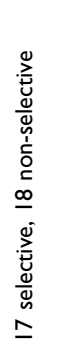 & $\stackrel{\infty}{m}$ & กิ & $\stackrel{f}{\stackrel{ \pm}{\prime}}$ & ถุ & $\stackrel{\infty}{m}$ & 으 & $\stackrel{\infty}{\sim}$ & 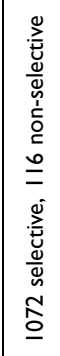 \\
\hline 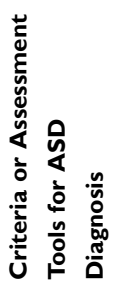 & $\tilde{z}$ & 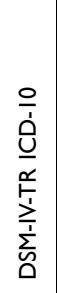 & $\sum_{\substack{i \\
\Delta}}^{\geq}$ & $\tilde{z}$ & $\sum_{\substack{n \\
\underline{n}}}^{\underline{n}}$ & 紊 & $\stackrel{\pi}{z}$ & 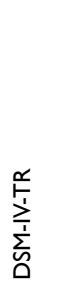 & $\underset{\sum}{\geq}$ & $\widetilde{\tilde{z}}$ & 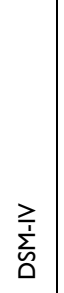 & $\tilde{z}$ & 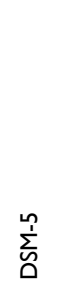 & $\sum_{\substack{n \\
\Delta}}^{\underline{n}}$ & $\stackrel{\pi}{z}$ & 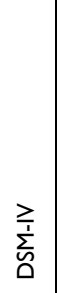 & $\underset{\substack{\geq \\
\Delta}}{\geq}$ & 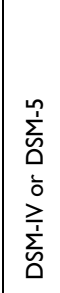 \\
\hline$\stackrel{\ddot{\check{\Sigma}}}{\ddot{\mathbf{L}}}$ & $\overline{\ddot{\ddot{n}}}$ & $\begin{array}{c}\overline{\dot{\alpha}} \\
\dot{q}+\dot{q}\end{array}$ & 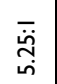 & 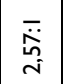 & $\overline{\ddot{\omega}}$ & $\tilde{z}$ & 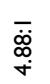 & 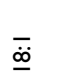 & 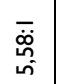 & $\begin{array}{l}\overline{\tilde{\hat{\sigma}}} \\
\stackrel{0}{0}\end{array}$ & $\underset{\ddot{m}}{\ddot{n}}$ & $\underset{\substack{\bar{\alpha} \\
\stackrel{\alpha}{+}}}{ }$ & 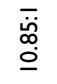 & $\underset{\infty}{\bar{m}}$ & 萨 & $\underset{\dot{m}}{\ddot{m}}$ & $\begin{array}{l}\overline{\ddot{m}} \\
\dot{m}\end{array}$ & $\tilde{z}$ \\
\hline 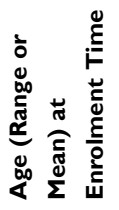 & $\begin{array}{l}\stackrel{\circ}{E} \\
\stackrel{\leftrightarrow}{\dot{y}}\end{array}$ & $\begin{array}{c}\frac{0}{1} \\
m \\
\lambda \\
\hat{a} \\
m \\
+ \\
+1 \\
\bar{\infty} \\
\infty\end{array}$ & $\begin{array}{l}\lambda \\
\bar{\lambda} \\
\bar{\lambda} \\
\lambda \\
\dot{j} \\
+1 \\
+1 \\
\dot{n}\end{array}$ & \begin{tabular}{|l|}
0 \\
$j$ \\
$\lambda$ \\
0 \\
0 \\
01 \\
0 \\
$i$ \\
$i$
\end{tabular} & $\frac{\hat{o}}{\hat{n}}$ & $\stackrel{\lambda}{\stackrel{\Lambda}{d}}$ & $\begin{array}{l}\overline{\bar{j}} \\
\dot{m} \\
\bar{\lambda} \\
\bar{j} \\
+1 \\
0 \\
0\end{array}$ & $\frac{\hat{0}}{\hat{n}}$ & 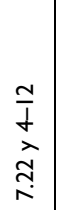 & $\frac{\hat{o}}{\gamma}$ & $\frac{\overrightarrow{\bar{T}}}{\bar{m}}$ & $\begin{array}{l}\overline{\bar{j}} \\
m \\
\bar{\lambda} \\
\bar{i} \\
+1 \\
0 \\
0 \\
0\end{array}$ & 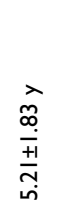 & 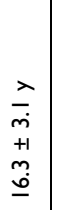 & $\stackrel{\vec{\alpha}}{\stackrel{\alpha}{d}}$ & 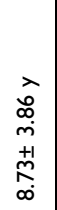 & 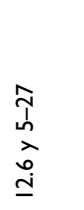 & $\begin{array}{l}\widehat{\widehat{T}} \\
\dot{\dot{d}} \\
\underline{\underline{E}}\end{array}$ \\
\hline 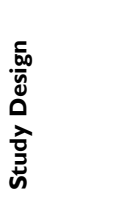 & 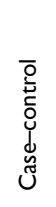 & 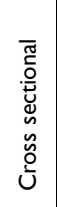 & 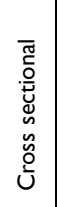 & 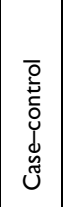 & 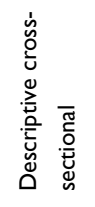 & 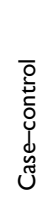 & 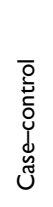 & 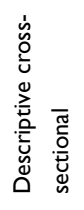 & 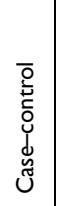 & 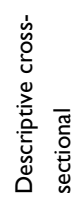 & 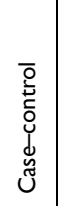 & 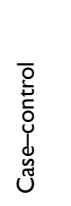 & 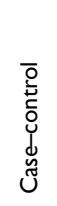 & 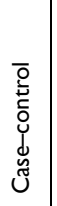 & 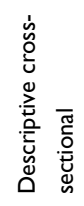 & 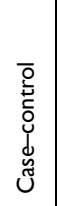 & 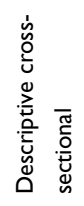 & 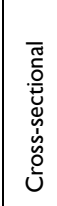 \\
\hline 홀 & 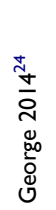 & 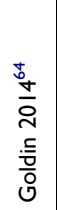 & 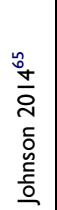 & 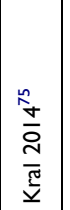 & 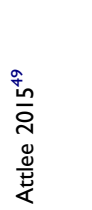 & 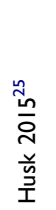 & 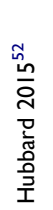 & 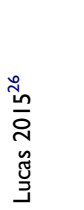 & 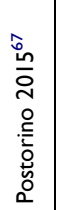 & 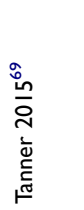 & 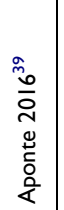 & 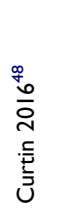 & 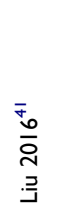 & 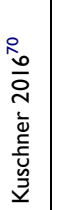 & 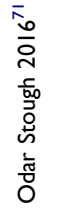 & 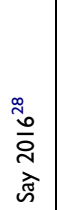 & 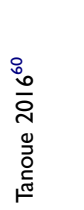 & 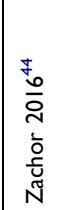 \\
\hline
\end{tabular}




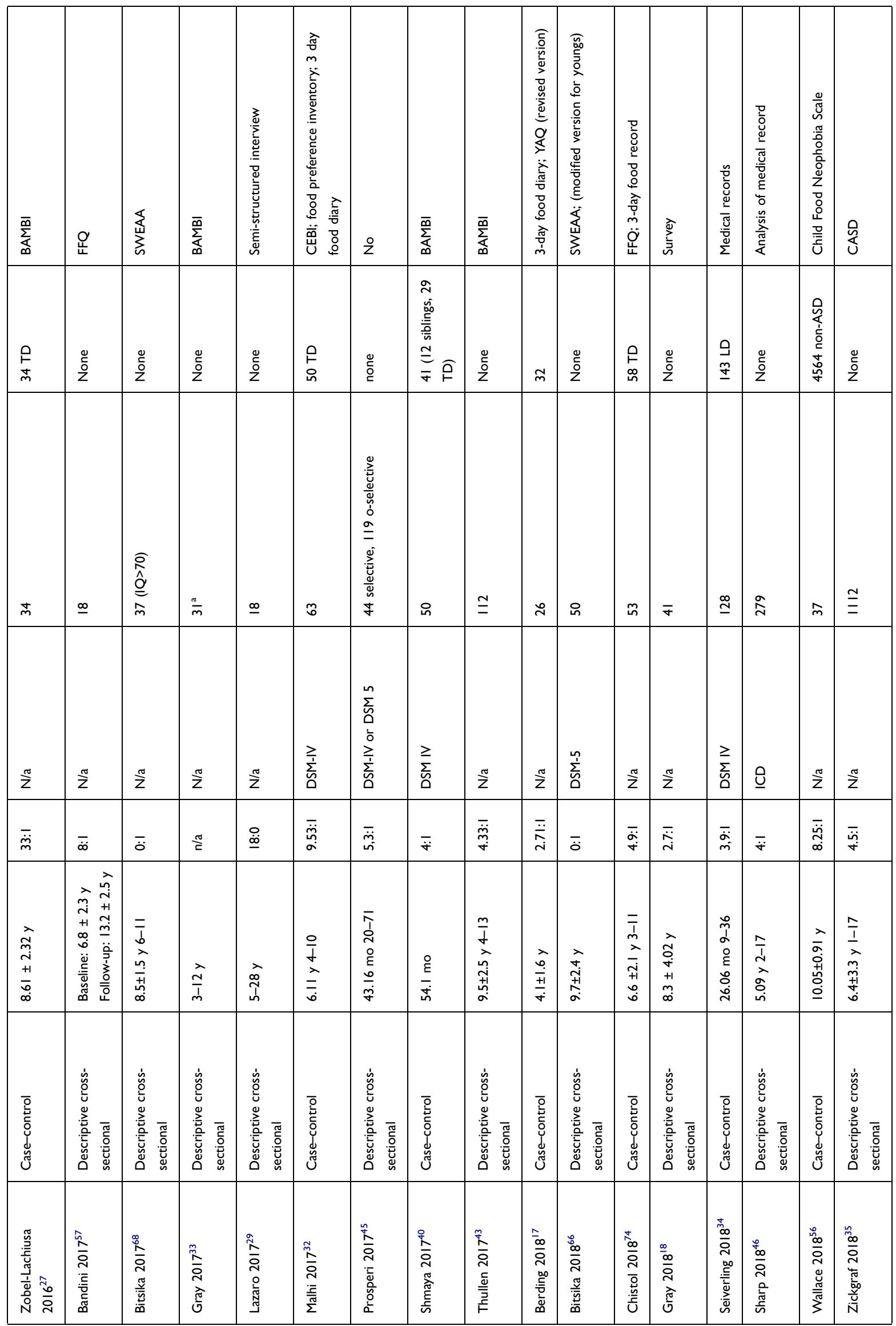




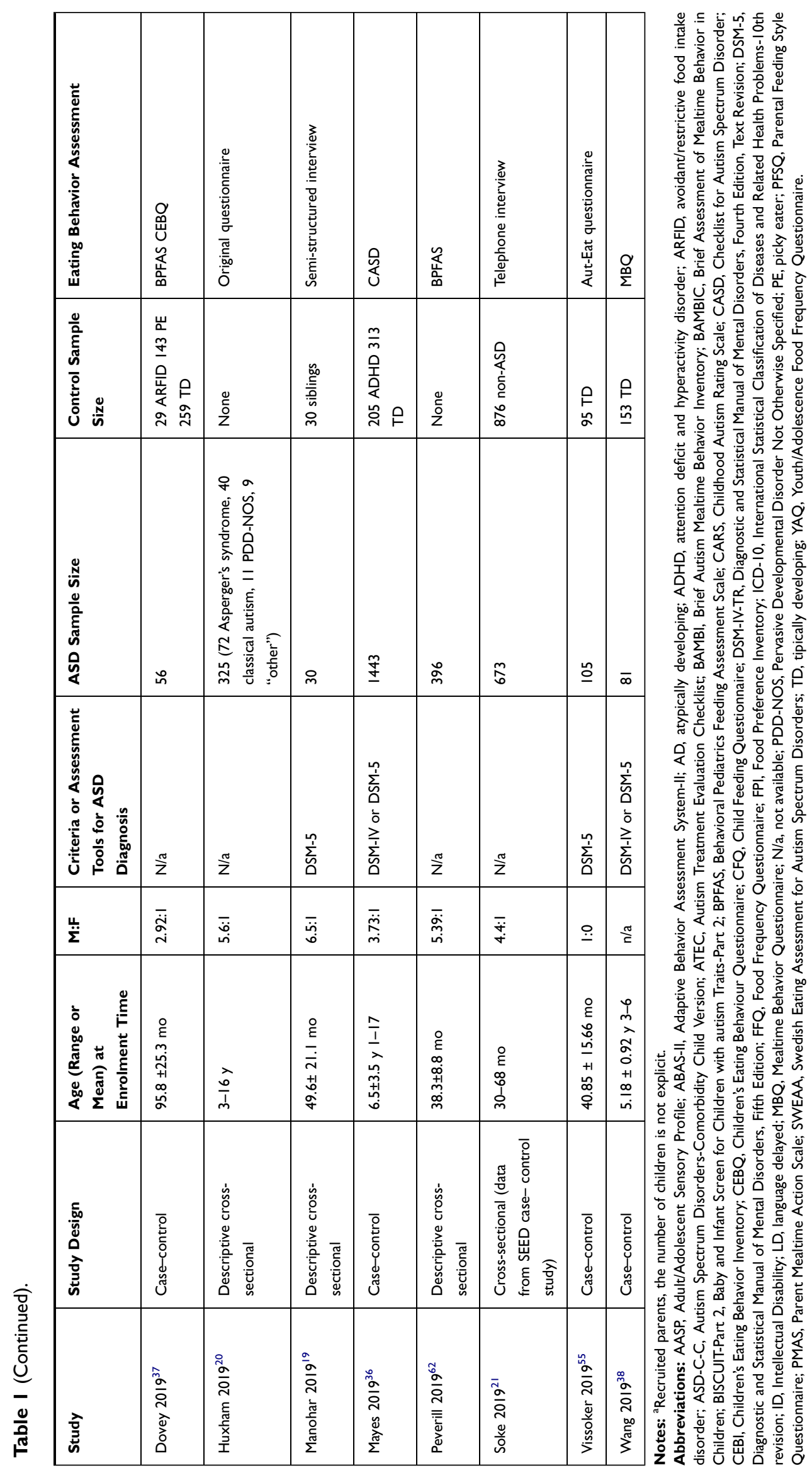


International Statistical Classification of Diseases (ICD) criteria in thirty studies. The others did not specify the diagnostic psychiatric classification system used to establish an ASD diagnosis.

ASD sample sizes ranged from 18 to 1747 participants. When present, the control group size ranged from 22 to 37,510 and it included: 1) typically developing (TD) subjects in fifteen studies; 2) subjects without an ASD diagnosis (called "non-ASD") in four cases; 3) population-based controls in three cases; 4) children diagnosed with other neurodevelopmental disorders in two cases; 5) siblings in one study; 6) mix of the precedents in five studies.

Eating behaviors were assessed through a standardized instrument in thirty-five works. The most common of them were the Brief Autism Mealtime Behavior Inventory (BAMBI), ${ }^{13}$ used by eleven researchers' teams, and the Food Frequency Questionnaire (FFQ), ${ }^{14}$ used by seven teams. Other standardized instruments were used in the remaining studies.

\section{Feeding History During Infancy}

Fifteen studies examined breastfeeding, weaning, and acceptance of solids in ASD children (Table 2). ${ }^{1615-29}$

\section{Breastfeeding}

Most of the studies showed some quantitative abnormalities of breastfeeding, such as low breastfeeding rate, short duration, and late initiation of breastfeeding.

In more detail, breastfeeding prevalence in ASD amounted to values between $70 \%$ and $85 \%,{ }^{15,16}$ which decreased to values between $20 \%$ and $76 \%$ when an exclusive assumption of breast milk was considered. ${ }^{17,19,20}$ Furthermore, the percentage of ASD children who had been breastfed for at least six months was estimated between $19 \%$ and $26 \%$. $^{20,21,25}$

Five studies compared breastfeeding rates between ASD children and non-ASD children. ${ }^{16,17,21,23,25}$ Two studies, among which a recent paper with major statistical and epidemiological power resulting from the adjustment for a long series of confounding factors, ${ }^{21}$ found that ASD children showed lower exclusive breastfeeding rates. ${ }^{17,21}$ Conversely, three studies found no differences. ${ }^{16,23,25}$

Six studies compared the breastfeeding length between the ASD population and healthy controls. ${ }^{19,21,22,24,25,28}$ Only in two studies was a similar length found, ${ }^{25,28}$ while four studies found a shorter duration in the ASD population. ${ }^{19,21,22,24}$ Conversely, ASD patients showed a higher breastfeeding duration in comparison with
Attention Deficit Hyperactivity Disorder (ADHD) children. $^{28}$

Only one paper presented data on the starting time of assumption of breast milk in the ASD population, identifying a later breastfeeding initiation compared to non-ASD children. ${ }^{22}$

One study investigated the relationship between the lack of breastfeeding and autism symptom severity, and they found no association. ${ }^{19}$

Four studies examined the qualitative aspects of breastfeeding. ${ }^{15,18,26,29}$ The most common difficulties were related to atypical sucking features: continuous, unorganized sucking, ${ }^{29}$ or vigorous sucking, not stopping with satiation. ${ }^{26}$ Other breastfeeding patterns, recognized in ASD children, were characterized by frequent breaks, fidgety, and frequent requests of feeding. ${ }^{18}$ Only one study compared qualitative breastfeeding abnormalities between ASD and TD children, finding no significant differences, likely due to its small sample size. ${ }^{15}$

\section{Weaning and Transition to Solid Foods}

Only three studies presented data on weaning or transition to solid foods. ${ }^{16,20,27}$ It has been described that $60.9 \%$ of ASD children received weaning before the sixth month of life. ${ }^{20}$ No differences in the age of transition from liquids to pureed foods have been identified between ASD and TD. ${ }^{27}$ Some problems with the progression from smooth purée to more textured foods ${ }^{20}$ or in the timing of the acceptance of solid food ${ }^{16}$ have been recognized. A delay in drinking from a cup and in feeding themselves using a fork was found in ASD children. ${ }^{27}$

\section{Eating and Mealtime Behaviors in Childhood and Adolescence}

Fifty-one studies evaluated eating and mealtime behaviors in ASD children and adolescents (Table 2).

\section{EP Epidemiology and Presentations}

ASD children showed a high prevalence of EP, with reported values between $43.6 \%$ and $96 \%{ }^{18,30-36}$ Their prevalence was found to be higher in ASD children compared to TD children, ${ }^{32,37,38}$ to siblings, ${ }^{39,40}$ and to children with other developmental disorders, such as $\mathrm{ADHD},{ }^{36}$ intellectual disability, ${ }^{31}$ and language delay. ${ }^{34}$

Among feeding abnormal patterns that could be found in ASD people during childhood, the most frequent is food selectivity (FS) ${ }^{17,35,41-43}$ which in turn includes more or less severe limitations in food acceptance. The prevalence 
Table 2 Studies' Results

\begin{tabular}{|c|c|c|}
\hline Study & Early Feeding History & Eating in Childhood and Adolescence \\
\hline Bandini $2010^{53}$ & & $\begin{array}{l}\text { Higher food refusal }(p<0.000 \mathrm{I}) \text {. more limited food } \\
\text { repertoire in ASD }(p<0.00 \mathrm{I}) \text {. }\end{array}$ \\
\hline Emond $2010^{16}$ & $\begin{array}{l}\text { No differences in breastfeeding rates; later acceptance of } \\
\text { solid foods ( } p=0.04 \text { ): } 61.8 \% \text { at } 0-3 \text { months, } 29.4 \% \text { at } 4 \\
\text { months, } 8.8 \% \text { at } 5 \text { months or more. }\end{array}$ & $\begin{array}{l}\text { Worsening of FS over the time. Higher difficulty to be fed } \\
(p<0.001) \text {; being choosy }(p<0.001) \text {; higher pica }(p<0.001) \text {. }\end{array}$ \\
\hline Provost $2010^{15}$ & No significant differences of breastfeeding features & $\begin{array}{l}\text { Higher difficulty in eating at some settings }(p<0.0 \mathrm{I}) \text {; } \\
\text { higher favorite food texture }(p<0.00 \mathrm{I}) \text {; higher mealtime } \\
\text { behavioral issues: frequent tantrums, throwing/dumping } \\
\text { food, picky eating, problems with gagging }(p<0.05) \text {, food } \\
\text { neophobia ( } p=0.0 \mathrm{I}) \text {; limiting to favorite textures }(p=0.02) \text {; } \\
\text { mouthing nonfood items }(p=0.006) \text {. }\end{array}$ \\
\hline Kozlowski $2011^{61}$ & & Higher eating problems $(p<0.05)$ \\
\hline Nadon $2011^{73}$ & & $\begin{array}{l}\text { Higher number of eating problems in children with tactile } \\
\text { sensitivity }(p<0.02 \text { I), taste/smell sensitivities }(p>0.000 \text { I), or } \\
\text { visual/auditory sensitivities }(p<0.006)\end{array}$ \\
\hline Zimmer $2011^{50}$ & & Lower food variety $(p<0.00 \mathrm{I})$ \\
\hline Al-farsi $2012^{22}$ & $\begin{array}{l}\text { Higher rate of initiation of breastfeeding after one hour } \\
\text { from birth }(78.1 \%, p=0.04) \text {, shorter duration of exclusive } \\
\text { breastfeeding }(p<0.05)\end{array}$ & \\
\hline Geier $2012^{42}$ & & $\begin{array}{l}\text { Very frequent eating problems ( } 94 \%) \text {; extremely limited } \\
\text { diet }(83 \%) \text {; eats too much/too little }(72 \%) \text {. }\end{array}$ \\
\hline Maskey $2012^{30}$ & & $\begin{array}{l}\text { Eating problems were the most common behavioral issue, } \\
\text { more frequent in children with lower language level } \\
(64.3 \%) \text { or attending special schools }(64.3 \%)\end{array}$ \\
\hline Beighley $2013^{54}$ & & $\begin{array}{l}\text { More FS in ASD than both the AD group and the TD } \\
\text { group }(p<0.001) \text {; decrease in FS across childhood in ASD } \\
\text { disorder group. }\end{array}$ \\
\hline Bicer $2013^{47}$ & & $\begin{array}{l}\text { Eating a limited variety of foods ( } 30 \%) \text {; food refusal ( } 16 \%) \text {. } \\
\text { Strategy used by parents: distraction ( } 25 \%) \text {, drink more } \\
\text { fluids ( } 23 \%) \text {, giving preferred foods ( } 18 \%)\end{array}$ \\
\hline Sharp $2013^{59}$ & & $\begin{array}{l}\text { Correlation between FS and problem behaviors (negative } \\
\text { vocalizations and disruptions during the meal) }(p<0.05) \mathrm{No} \\
\text { correlation between ASD symptom severity and FS }\end{array}$ \\
\hline Suarez $2013^{63}$ & & $\begin{array}{l}\text { Stable FS rate and severity and its association with sensory } \\
\text { sensitivity across the time over a period of two years }\end{array}$ \\
\hline Sun $2013^{51}$ & & $\begin{array}{l}\text { FS } 43.4 \%(p=0.003) \text {. Higher resistance in trying new foods } \\
(p<0.00 \mathrm{I}) \text { and inferior eating independence }(p<0.000 \mathrm{I})\end{array}$ \\
\hline Crasta $2014^{31}$ & & $\begin{array}{l}\text { Feeding problem more prevalent }(61 \%) \text { and severe } \\
(p<0.001) \text {; more prevalent in ASD children younger than } 6 \\
\text { years }(p=0.01) \text {; higher disruptive meal-time behaviors } \\
(p=0.02) \text { and food over-selectivity }(p=0.001) \text {; significant } \\
\text { correlations with sensory measures }(p<0.05) \text {, and autism } \\
\text { severity }(p=0.01)\end{array}$ \\
\hline
\end{tabular}

(Continued) 
Table 2 (Continued).

\begin{tabular}{|c|c|c|}
\hline Study & Early Feeding History & Eating in Childhood and Adolescence \\
\hline Field $2014^{23}$ & No differences in being breastfed at least four months & \\
\hline George $2014^{24}$ & $\begin{array}{l}\text { Association with breastfeeding duration (nil/less than } 6 \\
\text { months) }(p<0.00 \mathrm{I})\end{array}$ & \\
\hline Goldin $2014^{64}$ & & No differences neither in under-eating nor over-eating \\
\hline Johnson $2014^{65}$ & & $\begin{array}{l}\text { Association }(p<0.00 \mathrm{I}) \text { between feeding problems and } \\
\text { repetitive and ritualistic behaviors, sensory measures, and } \\
\text { externalizing and internalizing behavior; lack of association } \\
\text { with social and communication deficits, autism severity, and } \\
\text { cognitive levels }\end{array}$ \\
\hline Kral $2014^{75}$ & & $\begin{array}{l}\text { Greater food avoidance behaviors, including reluctance to } \\
\text { eat novel foods }(p=0.004) \text {, being selective about the range } \\
\text { of foods they accept ( } p=0.03 \text { ), in ASD children with } \\
\text { atypical oral sensory sensitivity than ASD children with } \\
\text { typical oral sensory sensitivity }\end{array}$ \\
\hline Attlee $2015^{49}$ & & $\begin{array}{l}69.6 \% \text { never/rarely cried/screamed during mealtimes; } 52 \% \\
\text { turned their face or body away from food; } 61 \% \text { expelled } \\
\text { food; } 59.1 \pm 20.6 \% \text { food refusal; higher preference for } \\
\text { starches }(55.8 \% \text { ) and least for protein }(32.6 \%) \text {; diets were } \\
\text { repetitive with limited variety }\end{array}$ \\
\hline Husk $2015^{25}$ & $\begin{array}{l}\text { No association with breastfeeding measures (being } \\
\text { breastfed, } 70.6 \% \text {; being exclusively breastfed for } 3 \text { months, } \\
50 \% \text {, or } 6 \text { months, } 24.6 \% \text { ) }\end{array}$ & \\
\hline Hubbard $2015^{52}$ & & $\begin{array}{l}\text { Higher food refusal based on consistency/texture } \\
(p<0.000 \mathrm{I}) \text {, brand }(p=0.0 \mathrm{I}) \text {, three or more of the listed } \\
\text { factors or none of them }(p<0.05)\end{array}$ \\
\hline Lucas $2015^{26}$ & $\begin{array}{l}\text { Vigorous sucking, not stopping with satiation reported for } \\
9 \text { children }\end{array}$ & \\
\hline Postorino $2015^{67}$ & & $\begin{array}{l}\text { Greater severity of ASD and lower cognitive abilities in FS } \\
\text { group compared to the No FS group }(p=0.023, p<0.00 \mathrm{I}) \text {. } \\
\text { Higher levels of parental stress in FS group compared to } \\
\text { the No FS group ( } p<0.00 \mathrm{I}) \text {. Parents of FS group reported } \\
\text { larger internalizing and externalizing symptoms }(p=0.002 \text {, } \\
p=0.0 \mathrm{II})\end{array}$ \\
\hline Tanner $2015^{69}$ & & $\begin{array}{l}\text { No significant association between selective eating and } \\
\text { behavioral variables }\end{array}$ \\
\hline Aponte $2016^{39}$ & & $\begin{array}{l}\text { Greater parents' concerns about the eating difficulties } \\
(p<0.001) \text { Higher severity of ASD symptomatology related } \\
\text { to greater levels of overall feeding difficulties ( } p=0.00 \text { I) } \\
\text { No correlation between the degree of selectivity of ASD } \\
\text { child and the degree of selectivity of his parent or his } \\
\text { sibling. }\end{array}$ \\
\hline Curtin $2016^{48}$ & & $\begin{array}{l}\text { FS } 66 \%(p<0.01) \text {, frequency of mealtime behaviors } \\
\text { problems, spousal stress, influence on what other family } \\
\text { members eat }\end{array}$ \\
\hline
\end{tabular}


Table 2 (Continued).

\begin{tabular}{|c|c|c|}
\hline Study & Early Feeding History & Eating in Childhood and Adolescence \\
\hline Liu $2016^{41}$ & & $\begin{array}{l}\text { Higher percentage of severe picky eating, severe resistance } \\
\text { to new food, reported general impression of severe eating } \\
\text { problems, constipation. No significant differences about } \\
\text { oral hypo-hypersensitivity, mild picky eating, mild } \\
\text { resistance to new food. }\end{array}$ \\
\hline Kuschner $2016^{70}$ & & $\begin{array}{l}\text { More likely to be food neophobic or afraid of eating new/ } \\
\text { unfamiliar foods }(p<0.00 \mathrm{I}) \text {, with lower parent ratings of } \\
\text { daily living skills, dislike textured foods }(p<0.00 \mathrm{I}) \text {, less } \\
\text { enjoy strong tastes }(p<0.005)\end{array}$ \\
\hline Odar Stough $2016^{71}$ & & $\begin{array}{l}\text { I/ } 3 \text { children consumed on average less than } 5 \text { different } \\
\text { foods daily; mean duration of a meal: } 17 \text { minutes; } 57.89 \% \text { of } \\
\text { children took a bite of the unfamiliar food, with lower } \\
\text { likelihood for children away from the table during their } \\
\text { meal }\end{array}$ \\
\hline Say $2016^{28}$ & $\begin{array}{l}\text { Higher breastfeeding duration in ASD and TD sample, than } \\
\text { in ADHD children }(p=0.005)\end{array}$ & \\
\hline Tanoue $2016^{60}$ & & $\begin{array}{l}\text { Changes in food history in response to new opportunities, } \\
\text { education and/or environment }\end{array}$ \\
\hline Zachor $2016^{44}$ & & $\begin{array}{l}9.8 \% \text { severe FS. The FS subgroup showed more severe } \\
\text { autism symptoms only as described by the parents, but not } \\
\text { per the professional assessment, and more impaired } \\
\text { adaptive skills. }\end{array}$ \\
\hline Zobel-Lachiusa $2016^{27}$ & $\begin{array}{l}\text { Higher mean age of drinking liquids from a cup }(p=0.02) \text {, } \\
\text { and of self-feeding using a fork }(p=0.00 \mathrm{I})\end{array}$ & Correlation with sensory measures $(p=0.00 \mathrm{I})$ \\
\hline Bandini $2017^{57}$ & & $\begin{array}{l}\text { At follow-up visit a reduction was found in: percentage of } \\
\text { FFQ items that child will not eat }(p=0.005) \text {; number of FFQ } \\
\text { items that child will not eat }(p=0.01) \text {; percentage of } \\
\text { vegetable FFQ items that child will not eat ( }(p=0.01) \text {; } \\
\text { percentage of fruit FFQ items that child will not eat } \\
(p=0.02) \text {; percentage of children who refuse foods based } \\
\text { on texture ( }(p=0.002) \text {; percentage of children who refuse } \\
\text { foods that are mixed together }(p=0.045)\end{array}$ \\
\hline Bitsika $2017^{68}$ & & $\begin{array}{l}\text { Association with restricted and repetitive behaviors } \\
(p=0.004)\end{array}$ \\
\hline Gray $2017^{33}$ & & $\begin{array}{l}\text { Higher limited variety and food refusal }(p<0.00 \mathrm{I}) .54 .2 \% \\
\text { prefer "crunchy" food; } 48 \% \text { not willing to try new foods, } \\
44 \% \text { dislike certain foods and will not eat them; } 38.5 \% \text { not } \\
\text { accepts or prefers a variety of foods; } 46 \% \text { not remain } \\
\text { seated at the table until the meal is finished; } 96 \% \text { aggressive } \\
\text { and } 92.3 \% \text { disruptive during mealtimes }\end{array}$ \\
\hline Lazaro $2017^{29}$ & Continuous, unorganized breastfeeding & $\begin{array}{l}\text { Autism-related factors may affect the child's food choices. } \\
\text { Environmental factors, particularly the parents' behavior, } \\
\text { may also play a decisive role }\end{array}$ \\
\hline
\end{tabular}

(Continued) 
Table 2 (Continued).

\begin{tabular}{|c|c|c|}
\hline Study & Early Feeding History & Eating in Childhood and Adolescence \\
\hline Malhi $2017^{32}$ & & $\begin{array}{l}79 \% \text { of parents expresses concern about FB of their ASD } \\
\text { children (vs } 64 \% \text { for TD); higher rate of feeding problems } \\
(0.001)\end{array}$ \\
\hline Prosperi $2017^{45}$ & & $\begin{array}{l}27 \% \text { FS More severe behavioral problems in selective ASD } \\
(p<.00 I) \text {. No difference in performance IQ and autism } \\
\text { severity }\end{array}$ \\
\hline Shmaya $2017^{40}$ & & $\begin{array}{l}\text { Higher limited variety }(p=0.005) \text {. No significant influence of } \\
\text { household preferences in the higher food aversion in ASD } \\
\text { group than sibling groups }\end{array}$ \\
\hline Thullen $2017^{43}$ & & $\begin{array}{l}62 \% \text { of participants report at least one FS behavior as } \\
\text { problematic.No significant association between FS and } \\
\text { parenting stress. Association between child disruptive } \\
\text { behavior at mealtime and quality of co-parenting }(p<0.05)\end{array}$ \\
\hline Berding $2018^{17}$ & Lower rate of exclusive breastfeeding $(20 \%, p<0.05)$ & $\begin{array}{l}\text { Higher percentage of children eating less than } 20 \text { foods } \\
(54 \%, p<0.05) \text {. No differences in picky eating and repetitive } \\
\text { eating pattern. }\end{array}$ \\
\hline Bitsika $2018^{66}$ & & $\begin{array}{l}\text { Inverse association with full IQ }(p=0.009) \text {, higher for } \\
\text { matrix reasoning subtest }(p<0.05)\end{array}$ \\
\hline Chistol $2018^{74}$ & & $\begin{array}{l}\text { Higher atypical sensory processing }(p<0.00 \mathrm{I}) \text {; association } \\
\text { between atypical oral sensory sensitivity and food refusal/ } \\
\text { eating vegetables }(p<0.00 \mathrm{I})\end{array}$ \\
\hline Gray $2018^{18}$ & Frequent breaks, fidgety, frequent requests of feeding & $\begin{array}{l}\text { Total mealtime behavior significantly higher in early } \\
\text { childhood }(p<0.00 \mathrm{I}) \text { and mid childhood }(p=0.005) \text { than } \\
\text { adolescence }\end{array}$ \\
\hline Seiverling $2018^{34}$ & & $\begin{array}{l}\text { FS by texture ( } p=0.004 ; 23.1 \% \text { ASD vs } 7.1 \% \text { LD); food } \\
\text { selectivity by type ( } p=0.036 ; 24.4 \% \text { ASD vs II.8\% LD), } \\
\text { new food refusal }(p=0.002 ; 10.3 \% \text { ASD vs } 0 \% \text { LD); Food } \\
\text { over-stuffing ( } p=0.016 ; 14.1 \% \text { ASD vs } 3.5 \% \text { LD) Presence of } \\
\text { one or more problem ( } p=0.00143 .6 \% \text { ASD vs } 20.0 \% \text { LD) }\end{array}$ \\
\hline Sharp $2018^{46}$ & & $\begin{array}{l}78 \% \text { with severe FS omitted one or more food groups } \\
\text { Problematic mealtime behaviors: Pushing away } 77.1 \% \text {; Head } \\
\text { turn } 72.8 \% \text {; Crying } 70 \% \text {; Leaving the table } 58.5 \% \text {; } \\
\text { Screaming } 45.7 \% \text {; Negative statements } 44.2 \% \text {; Throwing } \\
\text { things } 41.4 \% \text {; Disruptive behaviors } 28.5 \% \text {; Aggression } \\
22.8 \%\end{array}$ \\
\hline Wallace $2018^{56}$ & & $\begin{array}{l}\text { ASD children were more food neophobic than their non- } \\
\text { ASD peers }(p<0.001) \text {. }\end{array}$ \\
\hline Zickgraf $2018^{35}$ & & $\begin{array}{l}70 \% \text { of children showing atypical EB. Correlation with age } \\
\text { (most common at ages I-3) }(p=0.00 \mathrm{I}) \text {, increasing autism } \\
\text { severity }(p<0.000 \mathrm{I}) \text {, poor appetite }(p<0.000 \mathrm{I}) \text {, and } \\
\text { constipation }(p=0.0003 \text { ) }\end{array}$ \\
\hline Dovey $2019^{37}$ & & $\begin{array}{l}\text { Higher eating difficulties, behavioral problems and sensory } \\
\text { hypersensitivity }(p<0.002) \text { than in TD }\end{array}$ \\
\hline
\end{tabular}


Table 2 (Continued).

\begin{tabular}{|c|c|c|}
\hline Study & Early Feeding History & Eating in Childhood and Adolescence \\
\hline Huxham $2019^{20}$ & $\begin{array}{l}76 \% \text { initially exclusive breastfeeding, of which } 19.1 \%>6 \\
\text { months; } 60.9 \% \text { : early weaning; approxim. } 50 \% \text { : problems } \\
\text { with weaning and transition to textured foods }\end{array}$ & $\begin{array}{l}\text { Food acceptance influenced by food features ( } 51 \% \text { color, } \\
64.7 \% \text { food presentation); } 75.6 \% \text { limited variety (sensory } \\
\text { aspects and mealtime behavioral features also described) }\end{array}$ \\
\hline Manohar $2019^{19}$ & $\begin{array}{l}43.3 \% \text { exclusive breastfeeding; association with suboptimal } \\
\text { breastfeeding ( }<6 \text { months })(p=0.0162)\end{array}$ & \\
\hline Mayes $2019^{36}$ & & $\begin{array}{l}\text { Higher frequency of atypical eating behaviors in autism } \\
\text { ( } 70.4 \%) \text { than in children with other disorders (I3.1\%) and } \\
\text { typical children ( } 4.8 \%) 41.6 \% \text { only one atypical eating } \\
\text { behavior; } 58.9 \% \text { two or more; } 26.3 \% \text { three or more; } 88 \% \\
\text { FS; } 46 \% \text { hypersensitivity to food textures; } 27 \% \text { eating only } \\
\text { one brand of food; } 19 \% \text { pocketing food without } \\
\text { swallowing; I } 2 \% \text { pica. }\end{array}$ \\
\hline Peverill $2019^{62}$ & & $\begin{array}{l}\text { Four eating behavior trajectories: less severe and stable, } \\
\text { moderate and declining, severe and declining, very severe } \\
\text { and stable }\end{array}$ \\
\hline Soke $2019^{21}$ & $\begin{array}{l}\text { Lower breastfeeding rate }(85.7 \%, p=0.003) \text {. Shorter } \\
\text { breastfeeding duration }(p<0.0001) \text {, with } 26 \% \text { breastfed for } \\
>6 \text { months. }\end{array}$ & \\
\hline Vissoker $2019^{55}$ & & $\begin{array}{l}\text { Greater incidence of eating problems }(p>0.001) \text { Increase in } \\
\text { FS with increasing age }(p=0.014)\end{array}$ \\
\hline Wang $2019^{38}$ & & $\begin{array}{l}\text { Higher Total MBQ scores }(p<0.001) \text {. Atypical sensory } \\
\text { processing associated with abnormal mealtime behavior } \\
(p<0.05)\end{array}$ \\
\hline
\end{tabular}

Abbreviations: AD, atypically developing; TD, typically developing; ADHD, attention deficit and hyperactivity disorder; LD, language delay; ARFIDI, avoidant/restrictive food intake disorder; ASD-C-C, Autism Spectrum Disorders-Comorbidity Child Version; ATEC, Autism Treatment Evaluation Checklist; BAMBI, Brief Autism Mealtime Behavior Inventory; BISCUIT-Part 2, Baby and Infant Screen for Children with aUtlsm Traits-Part 2; BPFAS, Behavioral Pediatrics Feeding Assessment Scale; CARS, Childhood Autism Rating Scale; CASD, Checklist for Autism Spectrum Disorder; CEBI, Children's Eating Behavior Inventory; CEBQ, Children's Eating Behaviour Questionnaire; FFQ, Food Frequency Questionnaire; FPI, Food Preference Inventory; ID, Intellectual Disability; MBQ, Mealtime Behavior Questionnaire; PDD-NOS, Pervasive Developmental Disorder Not Otherwise Specified; FS, food selectivity; PE, picky eater; SP, Sensory Profile; SWEAA, Swedish Eating Assessment for Autism Spectrum Disorders.

of FS among ASD children and adolescents was extremely different among studies, with fluctuation between $9.8 \%$ and $83 \% .^{17,20,33,34,36,34,42-49}$ Most studies found a higher prevalence of FS in ASD children compared with TD controls. ${ }^{17,32,36,4050-56}$ However, one study found that a difference between ASD and TD children exists only when considering severe eating selectiveness, while no difference emerged about EP of mild severity. ${ }^{41}$

Other atypical eating behaviors have been identified in a child or adolescent with ASD, such as eating too little or too much, ${ }^{42}$ difficulty in remaining seated at the table all mealtime long, ${ }^{18,33,49}$ inflexibility about mealtime routines, ${ }^{33,43,49}$ ie, requesting of food prepared in a specific way, ${ }^{18}$ gagging ${ }^{15,18}$ closing the mouth tightly, ${ }^{33,49}$ aggressive or disruptive behaviors during mealtime, ${ }^{31,33,43,49}$ eating nonfood items or "pica,"15,16,36 and pocketing food without swallowing. ${ }^{36}$
EP in ASD children represented one common reason for parental concern, ${ }^{15,32,39,57-60}$ that progressively increased during the first year of life of the child. ${ }^{15}$ Evidence, in fact, suggested that EP are particularly common during early childhood in ASD children, ${ }^{61}$ then, in most cases, they tend to improve with age. ${ }^{18,31,35,36,62}$

In detail, there are some eating behaviors which appeared to be more common during early childhood in ASD children, such as playing with food, eating very slowly, craving certain food, requiring food to be prepared in a special way, stuffing mouth or cheeks, gagging, leaving the table, ${ }^{18}$ eating in some mealtime locations. ${ }^{15,18}$ On the other hand, there are few behaviors that seem to remain stable across childhood and adolescence, such as "having some food preferences" or "repetitive eating of certain foods." 18

Similarly, one study found that FS prevalence and severity remained stable in a group of ASD children longitudinally 
evaluated after a two-year period. ${ }^{63}$ However, other researchers found an increase of selectiveness over time, ${ }^{16,55}$ while still other authors found a decline in FS symptom severity ${ }^{54}$ and prevalence with the growth of the child. ${ }^{35}$

\section{EP and Neuropsychological Features}

The presence of cognitive impairment did not correlate with the presence or the severity of EP in ASD children. ${ }^{36,62,64,65}$ When focusing on high-functioning ASD individuals, it seems that the lower the intelligence quotient (IQ) the more severe the eating disturbance. ${ }^{66}$ In particular, the association between cognitive performance and the presence of eating disturbances was evaluated within a group of highfunctioning ASD girls (IQ>70), finding an inverse association between the full-scale IQ score and girls' self-rated abnormal eating behaviors. Studies considering the correlation between cognitive level and the presence of FS achieved contrasting results. In fact, comparing cognitive level between selective and non-selective children, one study found lower cognitive abilities in subjects with $\mathrm{FS},{ }^{67}$ while two studies did not identify any significant difference. ${ }^{44,45}$

Moreover, a higher prevalence of EP was found in children with lower expressive language skills. ${ }^{30}$

Using parental reports, four studies found that the presence of EP in ASD children was associated with a major severity of ASD symptoms, ${ }^{31,35,39,44}$ while only one study, conducted on a small sample of selective ASD children, found no association between FS and parental reports of autism symptom severity. ${ }^{59}$ Using professional assessment based on the direct observation of the child, only one study found major autism severity in selective ASD children, ${ }^{67}$ while two studies, characterized by larger samples, found no association. ${ }^{44,45}$ Some authors found no association between EP and social communication and interaction impairment severity, ${ }^{65,68}$ while an association with repetitive and restrictive behaviors was identified. ${ }^{45,65,68}$

Some studies recognized internalizing/externalizing behaviors in ASD patients with EP, in particular when the eating disturbance is more severe, ${ }^{45,65,67}$ although one study achieved contrasting results. ${ }^{69}$

The study of adaptive skills did not reveal significant differences between ASD individuals with or without $\mathrm{EP},{ }^{62,67}$ even if scarcer daily life skills have been found in ASD individuals with $\mathrm{FS}^{44}$ with food neophobia ${ }^{70}$ or with a moderate and declining subtype of EP. ${ }^{62}$

\section{EP and Behavioral and Environmental Factors}

Authors have identified a series of factors that could influence the FS of ASD children. Various behaviors in children could worsen FS, such as sipping more, playing, talking, or being away from the table during the meal. ${ }^{71}$ One study revealed that ASD children were more likely to refuse foods on the basis of their features than TD controls. $^{52}$ Food acceptance by ASD children could be influenced by various aspects of food such as its texture, consistency, color, temperature, smell, taste, but also presentation, brand, shape, or food mixed together. ${ }^{15,25,29,34-}$ 36,52,59,67,71 Prospective research has shown that ASD subjects, after the transition from childhood to adolescence, exhibited a reduction of food refusal based on texture and mixture. ${ }^{57}$ Furthermore, some studies reported that there were no differences between $\mathrm{ASD}$ and TD regarding color-based food refusal. ${ }^{32,52}$ Many studies have identified an association between sensory measures (assessed using the Sensory Profile scale ${ }^{72}$ ) and EP in ASD children, ${ }^{27,31,37,38,40,63,65,73-75}$ while this association was not significant according to only two studies. ${ }^{68,69}$

The strategies adopted by parents to cope with their children's FS are extremely different. One study reported that direct commands to eat from parents are more effective than other less directive strategies (trying to coax the child, giving additional commands, verbalizations) on inducing the child to take a bite of unfamiliar food. ${ }^{71}$ Parents often use praise or distractions, to allow the child to drink more or to eat his/her favorite food, to give rewards or, on the contrary, reprimands, and punishments. ${ }^{39,47}$

Although familial-derived food preferences have a limited effect on the FS of ASD children, ${ }^{39,40}$ mealtime behaviors and family context are suggested to be able to influence each other. On the one hand, parents' behaviors may be important in directing the child's diet in a healthy direction. $^{29}$ On the other hand, the presence of disruptive behaviors of the child during mealtime appeared to impact on life and quality of the relationship between parents. ${ }^{43}$ Whether FS is associated or not with parental stress is still debated and the two studies evaluating this association had conflicting results. One study found higher levels of parental stress in the FS group compared to the non-selective group, ${ }^{67}$ while another study showed no association between the two variables. $^{43}$ 


\section{Discussion}

\section{Feeding History During Infancy}

As well as some ASD clinical signs that may be identified during the first years of life, signs of dysregulated eating patterns may potentially be recognized early, ${ }^{76}$ when breastfeeding and weaning.

\section{Breastfeeding}

Breastfeeding abnormalities in ASD people have been suggested, but their full characterization is still an object of study. Literature has, in fact, focused both on quantitative and qualitative aspects of breastfeeding, achieving in most cases conflicting results.

According to data collected by the Centers for Disease Control and Prevention of Atlanta (www.cdc.gov/breast feeding/data/nis_data/index.htm), breastfeeding rate in the general population of the United States amounted on increasing values from $76 \%$ to $83 \%$ over the period 2009-2016, while the percentage of children being exclusively breastfed for six months has gone from $15 \%$ to $25 \%$ over the same period.

Similarly, recent studies included in this review estimated an analogous prevalence of breastfeeding and of exclusive breastfeeding for at least six months in the ASD population.

However, even if studies comparing breastfeeding rates and duration between ASD children and controls actually found conflicting results, according to a recent big metaanalysis, in which seven articles were included, ASD subjects $(\mathrm{N}=1463)$ were significantly less likely to have been breastfed than children without ASD $(\mathrm{N}=1180)$ $(p<0.002) .{ }^{77}$ In addition to these quantitative aspects, qualitative breastfeeding abnormalities in the ASD population have also been highlighted in the literature.

Although the data are conflicting, taken together, evidence supports the hypothesis of an association between breastfeeding features and ASD. The nature of the association between dysregulated breastfeeding and ASD is not well known. Breastfeeding pattern and duration are a result of the complex mother-child interaction, which is in turn determined both by the mother's characteristics and behaviors, and by child-related features (such as gestational age, health status, and neurodevelopmental system). ${ }^{26}$ Consequently, according to some authors, breastfeeding abnormalities may represent an early clinical sign of ASD, intrinsic of the child. As an example, the "continuous sucking" pattern, which is one of the most frequent atypical breastfeeding patterns in ASD, may be considered as a persistent repetitive behavior of the newborn. ${ }^{26}$ However, it is interesting to note that evidence on how much the dysregulated breastfeeding pattern represents an early clinical concern for parents and a reason for request of specialist consultation are inconclusive.

On the other hand, some authors suggested an etiopathogenetic link between breastfeeding and ASD. It is well known, in fact, that both genetics and the environmental factors play a role in the occurrence of ASD. Among environmental factors, optimal breastfeeding (defined as exclusive breastfeeding longer than 6 months according to World Health Organization recommendations ${ }^{78}$ ) has been suggested as protection against ASD in vulnerable children. ${ }^{19,22,77}$ If confirmed, its protective role may be explained by the peculiar and irreproducible composition of breast milk; ${ }^{79}$ in particular, it has been suggested that oxytocin, polyunsaturated fatty acids, ${ }^{80,81}$ but also Lactobacillus and Bifidobacterium contained in breast milk, may play a potential role in improving the neurodevelopmental outcome of the newborn. ${ }^{82-84}$

Most studies on breastfeeding features in the ASD population are based on parental reports, associated with a potential intrinsic recall bias, or retrospective analyses, which do not allow researchers to draw conclusions on the causality of a possible association. For this reason, further prospective longitudinal research with rigorous methodology is required to explore whether breastfeeding may have a potential pathophysiological role on the occurrence of ASD.

Evidence about the relationship between breastfeeding abnormalities and later EP development in ASD patients is very scarce. Gray et al, through a retrospective analysis of early feeding history in three groups of ASD children stratified according to age ranges, found that the "early childhood" group (2-6 years), compared to the "mid-childhood" and the "adolescents" groups, showed the highest prevalence of both past breastfeeding abnormalities and current EP. ${ }^{18}$ However, this finding is not sufficient to establish whether breastfeeding abnormalities may be a prelude to later EP. Thus, prospective studies on this topic are needed for a better understanding of breastfeeding abnormalities' predictive power of EP.

In any case, given that several benefits of breastfeeding in the general population have been described, health-care professionals should continue to encourage mothers to breastfeed their infants for at least 6 months.

\section{Weaning and Transition to Solid Foods}

About weaning timing and transition to solid foods in the ASD population, there are little available data. According to WHO guidelines, caregivers should start to feed infants 
with complementary foods at six months, ${ }^{85}$ while an earlier introduction of solids may give some benefits related to the development of food allergies, but evidence on this topic is still discordant. ${ }^{86,87}$

Data available for the ASD population suggest a similar weaning timing to that of the general pediatric population, ${ }^{20}$ while ASD children presented a delayed acceptance of textured foods and a delayed use of glasses and cutlery. As for breastfeeding, difficulties in the later acceptance of solids may be considered as early signs of ASD, in particular as early clinical presentations of the typical sameness, inflexibility, and fear of novelty in ASD children. ${ }^{16}$ Given the exiguity of available data on this matter, whether weaning-related difficulties may have a place among early predictive factors of ASD has still to be clarified. Slow learning to use cups and forks use could be framed in the general developmental delay, including for motor skills, that can be identified in many ASD children. However, it is important to note that, according to our knowledge, the link between early feeding difficulties and successive development of eating issues, ie, FS, has not been examined. Consequently, this could represent a future direction of research.

\section{Eating and Mealtime Behaviors in Childhood and Adolescence EP Epidemiology and Presentations}

Broadly defined, eating and feeding disturbances are relatively common among TD children, as a result of several contributing factors, both individual and environmental. ${ }^{88}$ Their prevalence in the general pediatric population is approximately $25-45 \%{ }^{88,89} \mathrm{~A}$ similar prevalence has been identified among children with different types of neurological impairments. ${ }^{90}$

In accordance with previous literature, ${ }^{91}$ recent studies have shown asignificantly higher prevalence of eating and feeding abnormalities among ASD children and adolescents.

In fact, a broad range of prevalence estimates has been identified, probably due to the lack of a universally accepted definition of feeding problems. The term feeding/eating disturbances includes a group of extremely heterogeneous clinical phenotypes, which may include abnormalities in the development of eating skills, difficulty in managing some foods, refusal of some food categories, lack of interest in food, or utilization of food as a comforter. ${ }^{88}$
Actually, in ASD patients several kinds of eating and mealtime behavioral disturbances have been recognized, among which, in accordance with previous literature, FS was reported as the most common. ${ }^{11}$ For FS a shared definition, as well as systematic criteria and approaches to identify it, are missing, making it difficult to compare literature results on the topic. The lack of a unique definition of FS is related to the amplitude of the concept. It represents, in fact, an umbrella term which covers multiple eating behaviors, as if they were different shades of one color, including picky eating, ie, a choosy approach to food, ${ }^{92}$ food refusal, ie, the refusal to eat all of most foods, ${ }^{93} \mathrm{FN}$, ie, the propensity to refuse to try unfamiliar food, ${ }^{56}$ limited food repertoire, ie, a limited variety of accepted food categories, ${ }^{94}$ repetitive eating pattern, ie, the propensity to always eat the same foods. ${ }^{95}$

Another reason for the huge variability of EP prevalence in ASD patients can be found in the sampling and methodological differences among studies. Size, demographical features, and clinical characterization of the enrolled sample change from one study to another. This aspect becomes of great relevance if we consider, for example, that eating profiles have been suggested to be different between males and females ${ }^{56}$ or according to age. ${ }^{18}$ Differently from TD children, in which early feeding difficulties are often transient and resolve spontaneously, ${ }^{88}$ eating disturbances in ASD subjects are frequently detectable from infancy to adulthood, with prevalence changing according to the considered age group. In particular, most studies suggested a decline of prevalence of EP over time, and an improvement of dietary habits with the growth. In reality, this data could be partly due to a change over time of parental perception of their child's eating, as children become more and more independent in their feeding and, simultaneously, parents progressively feed their children with their favorite food. ${ }^{18}$

In reality, a full description of EP changes from childhood to adolescence and, consequently, a detailed comparison among EP in different stages of pediatric age are not currently possible since the most of published papers on this topic cover a wide age range of their sample. Further prospective studies with a clear stratification of the sample according to age groups are desirable in order to better characterize the developmental trajectories of EP in ASD individuals, also considering that EP can impact on the health status of the child. Atypical eating patterns have been, in fact, considered as a risk factor for abnormalities in body weight $^{41,96,97}$ and in nutritional intake $\mathrm{e}^{41,98}$ in ASD patients. 


\section{EP and Neuropsychological Factors}

Findings about the association between eating abnormalities and some clinical features of ASD patients, as cognitive and language impairment, are still discordant.

Poorer daily living skills and more severe autism symptoms in ASD individuals with EP have often been identified through parents' reports. However, when a professional assessment on a child's functioning and symptoms was carried out, this association was not confirmed. A possible explanation for this discordance may be found in the negative impact that EP has on daily family life and on parents' perception of child functioning. Consequently, during the assessment, parents described their children's adaptive skills and autism symptoms as worse than they really are.

\section{EP and Behavioral and Environmental Factors}

Studies ${ }^{6,99-101}$ show that ASD patients are more likely to refuse food on the basis of several of their sensorial features, but, contrary to expectations, not based on color, although literature on this aspect is still discordant. ${ }^{99,102-104}$

Studies have consistently shown that eating disturbances in the ASD population are associated with higher SP scores. Thus, eating difficulties could be considered a consequence of sensory hypersensitivity, since the act of eating involves multiple senses as vision, touch, taste, and smell.

Moreover, sensory abnormalities in ASD individuals are very frequent, with a prevalence amounting on $70-95 \%$, and they may manifest themselves as hyper- or overresponsivity, under-responsivity, or sensory seeking. ${ }^{105}$ Hyperresponsivity is suggested to be the most common pattern in ASD patients. ${ }^{105}$ Furthermore, some evidence revealed that ASD individuals have a great frequency of sensory abnormalities, in particular in the domains of taste and smell. ${ }^{106,107}$ In this context, mealtime, made of changeable combinations of various sensorial stimuli, may represent a challenging experience for ASD individuals.

A link between a narrow diet and repetitive/ritualistic behaviors has been identified, suggesting that EP could be considered an extension of the features of rigidity and inflexibility, that are a hallmark of ASD people., ${ }^{6,93}$ However, whether mealtime disturbances, repetitive behaviors, and sensory hypersensitivity may represent a cluster of symptoms often seen together is yet not well defined.

Some children's or parents' mealtime behaviors can influence what/how much/how the child eats, as previously reported in the literature. ${ }^{93}$ In fact, a vicious cycle is often installed when parents allow children to choose how and what to eat, reinforcing their abnormal eating patterns. However, EP in ASD children is likely to be not due to their parents' behaviors, since studies comparing ASD children and their siblings found different eating and mealtime behavioral patterns.

Although some eating difficulties are related to intrinsic features of ASD, new eating habits may be introduced in the presence of an adequate environmental stimulus. ${ }^{29}$ Whether EP of ASD children may be considered the main cause of parental stress is still debated. Anyway, it is evident that educational programs for parents, including instructions on strategies to be adopted in order to reduce the occurrence of EP, are recommended.

\section{Conclusion}

EP in ASD children and adolescents represents a concern for parents and a potential cause of health issues. However, studies are very heterogeneous, showing methodological differences, so their results are difficult to compare. In addition, the absence of unique definitions of EP in ASD further limits the comparability of studies.

The current knowledge does not allow us to draw conclusions on the predictive power of eating disturbances when recognized in early childhood. Consequently, establishing the role of eating and mealtime behavior abnormalities as an early marker of ASD may be a future direction of research.

Future investigations on the implications of the behavioral profile, cognitive impairment, ASD severity, age, and sex on feeding and mealtime behaviors are needed, to better understand mechanisms beyond eating difficulties and to provide additional information useful to develop the most efficient intervention strategies for EP.

\section{Disclosure}

The authors report no conflicts of interest in this work.

\section{References}

1. APA. Diagnostic and Statistical Manual of Mental Disorders (DSM$\left.5^{\circledR}\right) .2013$.

2. Baio J, Wiggins L, Christensen DL, et al. Prevalence of autism spectrum disorder among children aged 8 years - autism and developmental disabilities monitoring network, 11 sites, United States, 2014. MMWR Surveill Summ. 2018;67(6):1-23. doi:10.15585/mmwr. ss6706a1

3. Ledford JR, Gast DL. Feeding problems in children with autism spectrum disorders: a review. Focus Autism Other Dev Disabl. 2006;21(3):153-166. doi:10.1177/10883576060210030401

4. Archer LA, Szatmari P. Eating and mealtime problems in young autistic children: prevalence and correlates. 1991

5. Cornish E. A balanced approach towards healthy eating in autism. $J$ Hum Nutr Diet. 1998;11(6):501-509. doi:10.1046/j.1365277X.1998.00132.x 
6. Ahearn WH, Castine T, Nault K, Green G. An assessment of food acceptance in children with autism or pervasive developmental disorder-not otherwise specified. J Autism Dev Disord. 2001;31 (5):505-511. doi:10.1023/A:1012221026124

7. Field D, Garland M, Williams K. Correlates of specific childhood feeding problems. J Paediatr Child Health. 2003;39(4):299-304. doi:10.1046/j.1440-1754.2003.00151.x

8. Collins MSR, Kyle R, Smith S, Laverty A, Roberts S, EatonEvans J. Coping with the usual family diet: eating behaviour and food choices of children with Down's syndrome, autistic spectrum disorders or cri du chat syndrome and comparison groups of siblings. J Learn Disabil. 2003;7(2):137-155. doi:10.1177/ 1469004703007002004

9. Schreck KA, Williams K, Smith AF. A comparison of eating behaviors between children with and without autism. J Autism Dev Disord. 2004;34(4):433-438. doi:10.1023/B:JADD.0000037419. 78531.86

10. Kerwin MLE, Eicher PS, Gelsinger J. Parental report of eating problems and gastrointestinal symptoms in children with pervasive developmental disorders. Child Heal Care. 2005;34 (3):217-234. doi:10.1207/s15326888chc3403_4

11. Vissoker RE, Latzer Y, Gal E. Eating and feeding problems and gastrointestinal dysfunction in Autism Spectrum Disorders. Res Autism Spectr Disord. 2015;12:10-21. doi:10.1016/j.rasd.2014.12.010

12. Klintwall L, Holm A, Eriksson M, et al. Sensory abnormalities in autism: a brief report. Res Dev Disabil. 2011;32(2):795-800. doi:10.1016/j.ridd.2010.10.021

13. Lukens CT, Linscheid TR. Development and validation of an inventory to assess mealtime behavior problems in children with autism. J Autism Dev Disord. 2008;38(2):342-352. doi:10.1007/ s10803-007-0401-5

14. Willet W. Food-frequency methods. In: Nutritional Epidemiology. 2nd ed. New York: Oxford University Press; 1998:74-100.

15. Provost B, Crowe TK, Osbourn PL, McClain C, Skipper BJ. Mealtime behaviors of preschool children: comparison of children with autism spectrum disorder and children with typical development. Phys Occup Ther Pediatr. 2010;30(3):220-233. doi: $10.3109 / 01942631003757669$

16. Emond A, Emmett P, Steer C, Golding J. Feeding symptoms, dietary patterns, and growth in young children with autism spectrum disorders. Pediatrics. 2010;126(2):e337-e342. doi:10.1542/ peds.2009-2391

17. Berding K, Donovan SM. Diet can impact microbiota composition in children with autism spectrum disorder. Front Neurosci. 2018;12:1-16. doi:10.3389/fnins.2018.00515

18. Gray HL, Sinha S, Buro AW, et al. Early history, mealtime environment, and parental views on mealtime and eating behaviors among children with ASD in Florida. Nutrients. 2018;10 (12):1867. doi:10.3390/nu10121867

19. Manohar H, Pravallika M, Kandasamy P, Chandrasekaran V, Rajkumar RP. Role of exclusive breastfeeding in conferring protection in children at-risk for autism spectrum disorder: results from a sibling case-control study. J Neurosci Rural Pract. 2018;9 (1):132-136. doi:10.4103/jnrp.jnrp_331_17

20. Huxham L, Marais M, van Niekerk E. Idiosyncratic food preferences of children with autism spectrum disorder in England South African J Clin Nutr. 2019;1-7.

21. Soke GN, Maenner M, Windham G, et al. Association between breastfeeding initiation and duration and autism spectrum disorder in preschool children enrolled in the study to explore early development. Autism Res. 2019;12(5):816-829. doi:10.1002/ aur.2091

22. Al-Farsi YM, Al-Sharbati MM, Waly MI, et al. Effect of suboptimal breast-feeding on occurrence of autism: a case-control study. Nutrition. 2012;28(7-8):e27-e32. doi:10.1016/j.nut.2012. 01.007
23. Field SS. Interaction of genes and nutritional factors in the etiology of autism and attention deficit/hyperactivity disorders: a case control study. Med Hypotheses. 2014;82(6):654-661. doi:10. 1016/j.mehy.2014.02.021

24. George B, Padmam MSR, Nair MKC, Leena ML, Russell PSS. CDC Kerala 14: early child care practices at home among children (2-6 y) with autism - a case control study. Indian J Pediatr. 2014;81(2):138-141. doi:10.1007/s12098-014-1602-5

25. Husk JS, Keim SA. Breastfeeding and autism spectrum disorder in the national survey of children's health. Epidemiology. 2015;26 (4):451-457. doi:10.1097/EDE.0000000000000290

26. Lucas RF, Cutler A. Dysregulated breastfeeding behaviors? $J$ Perinat Educ. 2015;24(3):171-180. doi:10.1891/1058-1243. 24.3.171

27. Zobel-Lachiusa J. Sensory differences and mealtime behavior in children with autism. Am J Occup Ther. 2016;70 (4_Supplement_1):7011505096p1. doi:10.5014/ajot.2016.70S1RP401C

28. Say GN, Karabekiroğlu K, Babadaği Z, Yüce M. Maternal stress and perinatal features in autism and attention deficit/hyperactivity disorder. Pediatr Int. 2016;58(4):265-269. doi:10.1111/ped.12822

29. Lázaro CP, Pondé MP. Narrativa de mães de crianças com transtorno do espectro do autismo: foco no comportamento alimentar. Trends Psychiatry Psychother. 2017;39(3):180-187. doi:10.1590/ 2237-6089-2017-0004

30. Maskey M, Warnell F, Parr JR, Le Couteur A, McConachie H. Emotional and behavioural problems in children with autism spectrum disorder. J Autism Dev Disord. 2013;43(4):851-859. doi:10.1007/s10803-012-1622-9

31. Crasta JE, Benjamin TE, Suresh APC, et al. Feeding problems among children with autism in a clinical population in India. Indian J Pediatr. 2014;81(2):169-172. doi:10.1007/s12098-0141630-1

32. Malhi P, Venkatesh L, Bharti B, Singhi P. Feeding problems and nutrient intake in children with and without autism: a comparative study. Indian J Pediatr. 2017;84(4):283-288. doi:10.1007/ s12098-016-2285-x

33. Gray HL, Chiang HM. Brief report: mealtime behaviors of Chinese American children with autism spectrum disorder. J Autism Dev Disord. 2017;47(3):892-897. doi:10.1007/s10803016-2993-0

34. Seiverling L, Towle P, Hendy HM, Pantelides J. Prevalence of feeding problems in young children with and without autism spectrum disorder: a chart review study. J Early Interv. 2018;40 (4):335-346. doi:10.1177/1053815118789396

35. Zickgraf H, Mayes SD. Psychological, health, and demographic correlates of atypical eating behaviors in children with autism. J Dev Phys Disabil. 2019;31(3):399-418. doi:10.1007/s10882018-9645-6

36. Mayes SD, Zickgraf H. Atypical eating behaviors in children and adolescents with autism, ADHD, other disorders, and typical development. Res Autism Spectr Disord. 2019;64:76-83. doi:10.1016/j.rasd.2019.04.002

37. Dovey TM, Kumari V, Blissett J. Eating behaviour, behavioural problems and sensory profiles of children with avoidant/restrictive food intake disorder (ARFID), autistic spectrum disorders or picky eating: same or different? Eur Psychiatry. 2019;61:56-62. doi:10.1016/j.eurpsy.2019.06.008

38. Wang GF, Li WL, Han Y, et al. Sensory processing problems and comorbidities in Chinese preschool children with autism spectrum disorders. J Autism Dev Disord. 2019;49(10):4097-4108. doi:10.1007/s10803-019-04125-7

39. Aponte CA, Romanczyk RG. Assessment of feeding problems in children with autism spectrum disorder. Res Autism Spectr Disord. 2016;21:61-72. doi:10.1016/j.rasd.2015.09.007 
40. Shmaya Y, Eilat-Adar S, Leitner Y, Reif S, Gabis LV. Meal time behavior difficulties but not nutritional deficiencies correlate with sensory processing in children with autism spectrum disorder. Res Dev Disabil. 2017;66:27-33. doi:10.1016/j.ridd.2017.05.004

41. Liu X, Liu J, Xiong X, et al. Correlation between nutrition and symptoms: nutritional survey of children with autism spectrum disorder in Chongqing, China. Nutrients. 2016;8(5):1-15. doi:10.3390/nu8050294

42. Geier DA, Kern JK, Geier MR. A prospective cross-sectional cohort assessment of health, physical, and behavioral problems in autism spectrum disorders. Maedica. 2012;7(3):193-200.

43. Thullen M, Bonsall A. Co-parenting quality, parenting stress, and feeding challenges in families with a child diagnosed with autism spectrum disorder. J Autism Dev Disord. 2017;47(3):878-886. doi:10.1007/s10803-016-2988-x

44. Zachor DA, Ben-Itzchak E. Specific medical conditions are associated with unique behavioral profiles in autism spectrum disorders. Front Neurosci. 2016;10:1-11. doi:10.3389/ fnins.2016.00410

45. Prosperi M, Santocchi E, Balboni G, et al. Behavioral phenotype of ASD preschoolers with gastrointestinal symptoms or food selectivity. J Autism Dev Disord. 2017;47(11):3574-3588. doi:10.1007/s10803-017-3271-5

46. Sharp WG, Postorino V, McCracken CE, et al. Dietary intake, nutrient status, and growth parameters in children with autism spectrum disorder and severe food selectivity: an electronic medical record review. J Acad Nutr Diet. 2018;118(10):1943-1950. doi:10.1016/j.jand.2018.05.005

47. Bicer AH, Alsaffar AA. Body mass index, dietary intake and feeding problems of Turkish children with autism spectrum disorder (ASD). Res Dev Disabil. 2013;34(11):3978-3987. doi:10.1016/j.ridd.2013.08.024

48. Curtin C, Hubbard K, Anderson SE, Mick E, Must A, Bandini LG. Food selectivity, mealtime behavior problems, spousal stress, and family food choices in children with and without autism spectrum disorder. J Autism Dev Disord. 2016;45 (10):3308-3315. doi:10.1007/s10803-015-2490-x

49. Attlee A, Kassem H, Hashim M, Obaid RS. Physical status and feeding behavior of children with autism. Indian $J$ Pediatr. 2015;82(8):682-687. doi:10.1007/s12098-015-1696-4

50. Zimmer MH, Hart LC, Manning-Courtney P, Murray DS, Bing NM, Summer S. Food variety as a predictor of nutritional status among children with autism. J Autism Dev Disord. 2012;42 (4):549-556. doi:10.1007/s10803-011-1268-Z

51. Sun C, Xia W, Zhao Y, Li N, Zhao D, Wu L. Nutritional status survey of children with autism and typically developing children aged 4-6 years in heilongjiang province, China. J Nutr Sci. 2013;2:1-8. doi:10.1017/jns.2013.9

52. Hubbard KL, Anderson SE, Curtin C, Must A, Bandini LG. A comparison of food refusal related to characteristics of food in children with autism spectrum disorder and typically developing children. J Acad Nutr Diet. 2014;114(12):1981-1987. doi:10.1016/j.jand.2014.04.017

53. Bandini LG, Anderson SE, Curtin C, et al. Food selectivity in children with autism spectrum disorders and typically developing children. $\quad J \quad$ Pediatr. 2010;157(2):259-264. doi:10.1016/j. jpeds.2010.02.013

54. Beighley JS, Matson JL, Rieske RD, Adams HL. Food selectivity in children with and without an autism spectrum disorder: investigation of diagnosis and age. Res Dev Disabil. 2013;34 (10):3497-3503. doi:10.1016/j.ridd.2013.07.026

55. Vissoker RE, Latzer Y, Stolar O, Rabenbach A, Gal E. Eating problems and patterns among toddlers and young boys with and without autism spectrum disorders. Res Autism Spectr Disord. 2019;59:1-9. doi:10.1016/j.rasd.2018.12.001
56. Wallace GL, Llewellyn C, Fildes A, Ronald A. Autism spectrum disorder and food neophobia: clinical and subclinical links. Am J Clin Nutr. 2018;108(4):701-707. doi:10.1093/ ajcn/nqy 163

57. Bandini L, Curtin C, Phillips S, Anderson SE, Maslin M, Must A. Changes in food selectivity in children with autism spectrum disorder. $J$ Autism Dev Disord. 2017;47(2):439-446. doi:10.1007/s10803-016-2963-6

58. Dewrang P, Sandberg AD. Parental retrospective assessment of development and behavior in Asperger syndrome during the first 2 years of life. Res Autism Spectr Disord. 2010;4(3):461-473. doi:10.1016/j.rasd.2009.11.003

59. Sharp WG, Jaquess DL, Lukens CT. Multi-method assessment of feeding problems among children with autism spectrum disorders. Res Autism Spectr Disord. 2013;7(1):56-65. doi:10.1016/j. rasd.2012.07.001

60. Tanoue K, Takamasu T, Matsui K. Food repertoire history in children with autism spectrum disorder in Japan. Pediatr Int. 2017;59(3):342-346. doi:10.1111/ped.13160

61. Kozlowski AM, Matson JL, Belva B, Rieske R. Feeding and sleep difficulties in toddlers with autism spectrum disorders. Res Autism Spectr Disord. 2012;6(1):385-390. doi:10.1016/j. rasd.2011.06.012

62. Peverill S, Smith IM, Duku E, et al. Developmental trajectories of feeding problems in children with autism spectrum disorder. J Pediatr Psychol. 2019;44(8):988-998. doi:10.1093/jpepsy/ jsz033

63. Suarez MA, Nelson NW, Curtis AB. Longitudinal follow-up of factors associated with food selectivity in children with autism spectrum disorders. Autism. 2014;18(8):924-932. doi:10.1177/ 1362361313499457

64. Goldin RL, Matson JL, Cervantes PE. The effect of intellectual disability on the presence of comorbid symptoms in children and adolescents with autism spectrum disorder. Res Autism Spectr Disord. 2014;8(11):1552-1556. doi:10.1016/j.rasd.2014.08.006

65. Johnson CR, Turner K, Stewart PA, et al. Relationships between feeding problems, behavioral characteristics and nutritional quality in children with ASD. J Autism Dev Disord. 2014;44 (9):2175-2184. doi:10.1007/s10803-014-2095-9

66. Bitsika V, Sharpley CF. An exploration of the association between matrix reasoning and eating disturbance behavior in girls with autism spectrum disorder. Psychol Res Behav Manag. 2018;11:259-266. doi:10.2147/PRBM.S166010

67. Postorino V, Sanges V, Giovagnoli G, et al. Clinical differences in children with autism spectrum disorder with and without food selectivity. Appetite. 2015;92:126-132. doi:10.1016/j. appet.2015.05.016

68. Bitsika V, Sharpley CF. Specific aspects of repetitive and restricted behaviours are of greater significance than sensory processing difficulties in eating disturbances in high-functioning young girls with ASD. J Dev Phys Disabil. 2018;30(2):259-267. doi:10.1007/s10882-017-9583-8

69. Tanner K, Case-Smith J, Nahikian-Nelms M, Ratliff-Schaub K, Spees C, Darragh AR. Behavioral and physiological factors associated with selective eating in children with autism spectrum disorder. $\mathrm{Am}$ J Occup Ther. 2015;69(6):p1-8. doi:10.5014/ajot.2015.019273

70. Kuschner ES, Eisenberg IW, Orionzi B, et al. A preliminary study of self-reported food selectivity in adolescents and young adults with autism spectrum disorder. Res Autism Spectr Disord. 2015;7:15-16.

71. Odar Stough C, Dreyer Gillette ML, Roberts MC, Jorgensen TD, Patton SR. Mealtime behaviors associated with consumption of unfamiliar foods by young children with autism spectrum disorder. Appetite. 2015;95:324-333. doi:10.1016/j.appet.2015.07.019

72. Dunn W. The sensory profile: examiner's manual. 1999. 
73. Nadon G, Feldman DE, Dunn W, Gisel E. Association of sensory processing and eating problems in children with autism spectrum disorders. Autism Res Treat. 2011;2011:1-8. doi:10.1155/2011/ 541926

74. Chistol LT, Bandini LG, Must A, Phillips S, Cermak SA, Curtin C. Sensory sensitivity and food selectivity in children with autism spectrum disorder. J Autism Dev Disord. 2018;48 (2):583-591. doi:10.1007/s10803-017-3340-9

75. Kral TVE, Souders MC, Tompkins VH, Remiker AM, Eriksen WT, Pinto-Martin JA. Child eating behaviors and caregiver feeding practices in children with autism spectrum disorders. Public Health Nurs. 2015;32(5):488-497. doi:10. 1111/phn.12146

76. Parmeggiani A, Corinaldesi A, Posar A. Early features of autism spectrum disorder: a cross-sectional study. Ital J Pediatr. 2019;45 (1):1-8. doi:10.1186/s13052-019-0733-8

77. Tseng PT, Chen YW, Stubbs B, et al. Maternal breastfeeding and autism spectrum disorder in children: a systematic review and meta-analysis. Nutr Neurosci. 2019;22(5):354-362. doi:10.1080/ 1028415X.2017.1388598

78. Kramer MS, Kakuma R. Optimal duration of exclusive breastfeeding. Cochrane Database Syst Rev. 2012;8.

79. Hong L, Ziegler J, Rebecca B. Breastfeeding and autism spectrum disorders. Top Clin Nutr. 2014;29(3):278-285. doi:10.1097/ TIN.0000000000000005

80. Cheng J, Eskenazi B, Widjaja F, Cordero JF, Hendren RL. Improving autism perinatal risk factors: a systematic review. Med Hypotheses. 2019;127:26-33. doi:10.1016/j.mehy.2019.03.012

81. Bar S, Milanaik R, Adesman A. Long-term neurodevelopmental benefits of breastfeeding. Curr Opin Pediatr. 2016;28 (4):559-566. doi:10.1097/MOP.0000000000000389

82. Le Hurou-luron I, Blat S, Boudry G. Breast- v. formula-feeding: impacts on the digestive tract and immediate and long-term health effects. Nutr Res Rev. 2010;23(1):23-36. doi:10.1017/ S0954422410000065

83. Sinkiewicz G, NordstrÖm E. Occurrence of lactobacillus reuteri, lactobacilli and bifidobacteria in human breast milk: 353. Pediatr Res. 2005;58(2):415. doi:10.1203/00006450-200508000-00382

84. Fasano A, Hill I. Serum zonulin, gut permeability, and the pathogenesis of autism spectrum disorders: cause, effect, or an epiphenomenon? Journal of Pediatrics. 2017;188:15-17. doi:10.1016/j.jpeds.2017.05.038

85. WHO, PAHO. Guiding principles for complementary feeding of the breastfed child. Washington DC:World Health Organization, 2003.

86. Abrams EM, Greenhawt M, Fleischer DM, Chan ES. Early solid food introduction: role in food allergy prevention and implications for breastfeeding. J Pediatr. 2017;184:13-18. doi:10.1016/j. jpeds.2017.01.053

87. Caffarelli C, Di Mauro D, Mastrorilli C, Bottau P, Cipriani F, Ricci G. Solid food introduction and the development of food allergies. Nutrients. 2018;10(11):1-12. doi:10.3390/nu10111790

88. Bryant-Waugh R, Markham L, Kreipe RE, Walsh BT. Feeding and eating disorders in childhood. Int $J$ Eat Disord. 2010;43 (2):98-111. doi:10.1002/eat.20795

89. Benjasuwantep B, Chaithirayanon S, Eiamudomkan M. Feeding problems in healthy young children: prevalence, related factors and feeding practices. Pediatr Rep. 2013;5(2):38-42. doi:10.4081/pr.2013.e10

90. Andrew MJ, Sullivan PB. Feeding difficulties in disabled children. Paediatr Child Health. 2010;20(7):321-326. doi:10.10 16/j.paed.2010.02.005

91. Volkert VM, Vaz PCM. Recent studies on feeding problems in children with autism. J Appl Behav Anal. 2010;43(1):155-159. doi:10.1901/jaba.2010.43-155
92. Taylor CM, Wernimont SM, Northstone K, Emmett PM. Picky/ fussy eating in children: review of definitions, assessment, prevalence and dietary intakes. Appetite. 2015;95:349-359. doi:10. 1016/j.appet.2015.07.026

93. Williams KE, Seiverling L. Eating problems in children with Autism Spectrum Disorder. Top Clin Nutr. 2010;25(1):22-37. doi:10.1097/TIN.0b013e3181d10958

94. Marí-Bauset S, Zazpe I, Mari-Sanchis A, Llopis-González A, Morales-Suárez-Varela M. Food selectivity in autism spectrum disorders: a systematic review. J Child Neurol. 2014;29 (11):1554-1561. doi:10.1177/0883073813498821

95. Cermak SA, Curtin C, Bandini LG. Food selectivity and sensory sensitivity in children with autism spectrum disorders. $J$ Am Diet Assoc. 2010;110(2):238-246. doi:10.1016/j.jada.2009.10.032

96. Curtin C, Jojic M, Bandini LG. Obesity in children with autism spectrum disorder. Harv Rev Psychiatry. 2014;22(2):93-103. doi:10.1097/HRP.0000000000000031

97. Hyman SL, Stewart PA, Schmidt B, et al. Nutrient intake from food in children with autism. Pediatrics. 2012;130(SUPPL. 2): S145-S153. doi:10.1542/peds.2012-0900L

98. Graf-Myles J, Farmer C, Thurm A, et al. Dietary adequacy of children with autism compared with controls and the impact of restricted diet. J Dev Behav Pediatr. 2013;34(7):449-459. doi:10.1097/DBP.0b013e3182a00d17

99. Nadon G, Feldman DE, Dunn W, Gisel E. Mealtime problems in children with autism spectrum disorder and their typically developing siblings: a comparison study. Autism. 2011;15(1):98-113. doi:10.1177/1362361309348943

100. Bennetto L, Kuschner ES, Hyman SL. Olfaction and taste processing in autism. Biol Psychiatry. 2007;62(9):1015-1021. doi:10.1016/j.biopsych.2007.04.019

101. Rogers SJ, Hepburn S, Wehner E. Parent reports of sensory symptoms in toddlers with autism and those with other developmental disorders. J Autism Dev Disord. 2003;33(6):631-642. doi:10.1023/B:JADD.0000006000.38991.a7

102. Johnson CR, Handen BL, Mayer-Costa M, Sacco K. Eating habits and dietary status in young children with autism. J Dev Phys Disabil. 2008;20(5):437-448. doi:10.1007/s10882-008-9111-y

103. Lockner DW, Crowe TK, Skipper BJ. Dietary intake and parents' perception of mealtime behaviors in preschool-age children with autism spectrum disorder and in typically developing children. $J$ Am Diet Assoc. 2008;108(8):1360-1363. doi:10.1016/j. jada.2008.05.003

104. Dominick KC, Davis NO, Lainhart J, Tager-Flusberg H, Folstein S. Atypical behaviors in children with autism and children with a history of language impairment. Res Dev Disabil. 2007;28(2):145-162. doi:10.1016/j.ridd.2006.02.003

105. Hazen EP, Stornelli JL, O'Rourke JA, Koesterer K, McDougle CJ. Sensory symptoms in autism spectrum disorders. Harv Rev Psychiatry. 2014;22(2):112-124. doi:10.1097/01. HRP.0000445143.08773.58

106. Schoen SA, Miller LJ, Brett-Green BA, Nielsen DM. Physiological and behavioral differences in sensory processing: a comparison of children with autism spectrum disorder and sensory modulation disorder. Front Integr Neurosci. 2009;3:29. doi:10.3389/neuro.07.029.2009

107. Leekam SR, Nieto C, Libby SJ, Wing L, Gould J. Describing the sensory abnormalities of children and adults with autism. J Autism Dev Disord. 2007;37(5):894-910. doi:10.1007/s10803006-0218-7 


\section{Publish your work in this journal}

Neuropsychiatric Disease and Treatment is an international, peerreviewed journal of clinical therapeutics and pharmacology focusing on concise rapid reporting of clinical or pre-clinical studies on a range of neuropsychiatric and neurological disorders. This journal is indexed on PubMed Central, the 'PsycINFO' database and CAS, and is the official journal of The International Neuropsychiatric Association (INA). The manuscript management system is completely online and includes a very quick and fair peer-review system, which is all easy to use. Visit http://www.dovepress.com/testimonials.php to read real quotes from published authors.

Submit your manuscript here: https://www.dovepress.com/neuropsychiatric-disease-and-treatment-journal 